Cómo citar este trabajo: Fernández García, F., Herrera Arenas, D., \& Fernández Bustamante, C. (2021). Temporal and territorial dimension of the COVID-19 pandemic in Asturias, Spain. Boletín de la Asociación de Geógrafos Españoles, (91). https://doi.org/10.21138/bage.3147

\title{
Dimensión temporal y territorial de la pandemia COVID-19 en Asturias
}

\author{
Temporal and territorial dimension \\ of the COVID-19 pandemic in Asturias, Spain
}

\section{Felipe Fernández García}

felipe@uniovi.es

\section{Daniel Herrera Arenas}

herreradanie|@uniovi.es

\section{Cristina Fernández Bustamante}

cristina@observatoriodelterritorio.es

Observatorio del Territorio, Departamento de Geografía

Universidad de Oviedo (España)

\section{Resumen}

Tras analizar las fuentes disponibles para estudiar la incidencia de la COVID-19 en Asturias, se aborda el estudio de la evolución diaria de la pandemia en la región a lo largo de 360 jornadas, comparándola con la del conjunto del país, y tratando de determinar las causas que explican la aparición y desarrollo de las tres olas detectadas, y la existencia de periodos de baja incidencia. Se aborda a continuación el análisis de las diferencias intrarregionales mediante el estudio de los valores a escala municipal, relacionando los desiguales registros observados con la estructura del poblamiento y con el grado de envejecimiento de la población. Se concluye que la evolución de la pandemia en Asturias presenta unos rasgos similares a la del conjunto del país, aunque con singularidades, derivadas en un primer momento de las medidas de restricción adoptadas y de 
la facilidad para el control de los intercambios con el exterior, y posteriormente de la relajación generada por el proceso de apertura y la sensación de seguridad producida por la existencia de un largo periodo sin casos. Se concluye asimismo que la concentración de la población en las áreas urbanas facilitó la proliferación en ellas de casos detectados.

Palabras clave: poblamiento; envejecimiento; pautas residenciales.

\begin{abstract}
After analyzing the available sources to study the incidence of COVID-19 in Asturias, the study of the daily evolution of the pandemic in the region over 360 days is approached, comparing it with that of the country as a whole, and trying to determine the causes that explain the appearance and development of the three waves detected, and the existence of periods of low incidence. The analysis of intra-regional differences is addressed below by studying the values at the municipal level, relating them to the uneven records observed with the structure of the settlement and the degree of aging of the population. It is concluded that the evolution of the pandemic in Asturias presents similar characteristics to that of the country as a whole, although with singularities, derived initially from the restriction measures adopted and from the ease of controlling foreign trade, and later the relaxation generated by the opening process and the feeling of security produced by the existence of a long period without cases. It is also concluded that the concentration of the population in urban areas facilitated the proliferation of detected cases in them.
\end{abstract}

Keywords: population; aging; residential guidelines.

\title{
1 Introducción
}

La geografía y la epidemiología tienen ámbitos de confluencia en cuanto al análisis y representación espacial de fenómenos demográficos, en este caso sobrevenidos de una mortalidad excepcional como consecuencia de una crisis sanitaria. Cuestiones como la estructura demográfica, los movimientos migratorios, las condiciones ambientales o sociales, los movimientos pendulares, etc., son algunas de las cuestiones que pueden tener relación con el desarrollo o expansión de las enfermedades. Podríamos afirmar que el territorio impone ciertos condicionantes que pueden determinar o agravar las consecuencias en la salud pública.

La relación entre análisis espacial y epidemiología tiene sus orígenes remotos a finales del siglo XVIII y a comienzos del XIX, plasmados en el mapa de Nueva York que Valentine Seaman 
publicó en 1798, o el de Natchez elaborado por Cartwright en 1826, coincidiendo ambos trabajos en el objetivo de buscar factores que explicasen los patrones de distribución geográfica de la fiebre amarilla en Estados Unidos (Ocaña-Riola \& Sanchez-Cantalejo, 2020). Ambos trabajos se centraron en el intento de detectar el patrón geográfico de la enfermedad, relacionando la extensión espacial de la epidemia con factores como la temperatura, la humedad o la concentración de insectos en el aire. Los estudios epidemiológicos con base geográfica continuaron a lo largo del siglo XIX, siendo sin duda el más relevante el mapa de la distribución de la epidemia de cólera que afectó al barrio londinense del Soho en 1854, obra de John Snow (Hempel, 2020). Mención especial merece también el estudio sobre la epidemia de cólera sufrida en España en 1884-1885 (Hauser, 1887).

Pero más allá de las revisiones que se han hecho de las epidemias, desde las plagas de la antigüedad hasta la COVID-19 (Sardon, 2020), o del análisis de los aspectos geográficos, ecológicos o históricos que están en su base (Buj, 2020), la actual pandemia ha servido para que, desde el campo de la geografía, se haya producido un movimiento de análisis y reflexión que abarca diferentes escenarios.

En unos casos tal análisis se ha concretado en la reunión de colaboraciones provenientes de muchos países del mundo con el objeto de revisar las diversas perspectivas teóricas, los distintos enfoques metodológicos y los diferentes focos temáticos "para comprender mejor las geografías desiguales del Coronavirus" (Rose-Redwood et al., 2020), o bien con el de analizar la producción del conocimiento geográfico bajo la COVID-19 en lo tocante a la gobernanza, a la geopolítica, a las geografías sociales, a las económicas, a las regionales o a las urbanas (Aalbers et al., 2020).

En otros casos se trata de trabajos que focalizan su atención en aspectos muy diversos. La extensión de la urbanización analizada como una variable determinante de los comportamientos de la pandemia (Connolly et al., 2020); el análisis de la movilidad para identificar las nuevas formas de desigualdad y las dificultades que se están generando (Bissell, 2021); los cambios producidos en las relaciones entre lugar de trabajo y lugar de residencia y, por extensión, entre espacios urbanos y áreas rurales (Dummont, 2021; Klapka et al., 2020; Reuschke \& Felstead, 2020); las selectividades espaciales plasmadas en desiguales impactos sociales entre lugares, localidades, comunidades y vecindarios (Chen, 2020); o en la manera en la que las divisiones territoriales han incidido en de la vida cotidiana, en los individuos y en las organizaciones políticas, en la tarea de buscar un lugar seguro para sobrevivir al virus (Yılmaz, 2020). 
En otros, finalmente, los trabajos se centran en el estudio del impacto de la COVID-19 en ámbitos territoriales concretos.

Se trata, de un lado, de análisis supranacionales, como el realizado sobre 119 economías regionales en 9 países de la Unión Europea con el objeto de buscar explicación a los factores subyacentes a la pandemia, indagando acerca de cómo la calidad del aire, la demografía, la interconexión global, las tendencias de urbanización, las tendencias históricas en el gasto en salud y las políticas implementadas para mitigar la pandemia han influido en una tasa de mortalidad regionalmente desigual (Kapitsinis, 2020); el que tiene como objeto de atención el impacto regional desigual de la COVID-19 en los países del sur de la Unión Europea (Gialis \& Kapitsinis, 2020); o el que explora los patrones espacio-temporales de la pandemia a escala regional europea y a escala de país, concretado en Dinamarca (Holmager et al., 2020).

Precisamente es en la escala nacional en la que la producción de estudios sobre las relaciones espacio-temporales de la pandemia han sido más abundantes a lo largo de los últimos meses. Es el caso de los trabajos sobre Inglaterra, donde se aborda el proceso de concentración de los efectos de la pandemia en las comunidades postindustriales del norte del país, caracterizadas por formas de desigualdad arraigadas histórica y geográficamente (Robinson et al., 2020); el de Grecia, donde se aborda el análisis del aumento del desempleo, a pesar del plan de recuperación económica adoptado por el gobierno griego, y la desigual huella que en términos espaciales ha generado la COVID-19 en la crisis del empleo (Kapitsinis \& Sykas, 2020); el de Italia, donde se estudia el impacto de las restricciones de movilidad durante el brote de COVID19 (Scala et al., 2020), la evolución de los contagios a nivel nacional y lombardo (Casti, 2020), - la propagación subnacional de la pandemia desde una perspectiva de geografía económica (Ascani et al., 2021); el de Dinamarca, que investiga la situación de la COVID-19 en las áreas geográficas del país a lo largo del tiempo, concluyendo que han sido las regiones del este, especialmente la Región Capital, las más afectadas (Holmager et al., 2020); el de Alemania, que se ocupa de identificar los procesos clave de difusión de la enfermedad en el espacio, para con ello tratar de explicar los patrones espaciales (Kuebart \& Stabler, 2020); el de Polonia, donde se pone la atención en los efectos de la contracción urbana, el transindustrialismo, la minería del carbón y el policentrismo (Krzysztofik et al., 2020); el de Rumanía, que, tras un análisis del proceso, considera algunas de las posibles implicaciones de la pandemia a largo plazo para el país (Remus \& Light, 2020); el de los Países Bajos, que investiga el papel de la densidad de población (Boterman, 2020); el de Portugal, que incide en la expresión geográfica del número de casos confirmados (Marques da Costa \& Marques da Costa, 2020); o el de España, que 
analiza la rapidez del proceso de expansión de la COVID-19 (Perez-Bermejo \& Murillo-Llorente, 2020).

Fuera del ámbito europeo cabe señalar los trabajos que tienen por objeto de atención la situación en Estados Unidos, donde se examina el papel de la estructura espacial en la configuración de las disparidades geográficas (Sun et al., 2020), o los determinantes de la rapidez con la que la pandemia creció en diferentes condados (Wheaton \& Kinsella Thompson, 2020) . También hay estudios relativos a otros países, como el que analiza la evolución, la distribución espacial y la difusión temporal del virus en Argentina (Ramirez, 2020); el que investiga los resultados de la enfermedad en cuanto a su incidencia por departamentos y distritos en Colombia (Pinzón, 2020); o el que describe las distribuciones temporales, geográficas y de población de la COVID-19 en China en los primeros momentos de la pandemia.

Por lo que respecta a España, además del trabajo realizado sobre Palma (Mallorca), donde se incide en las brechas sociales y económicas, y en las débiles condiciones sociales, económicas y de vivienda para hacer frente a la crisis (González Pérez, 2020), son varios los grupos de investigación universitarios que han realizado análisis sobre la incidencia de la COVID-19 en nuestro país, y que han plasmado sus resultados en portales web, como es el caso del Grupo de Estudios en Ordenación del Territorio de la Universidad de Zaragoza, que ha realizado cartografías a diferentes escalas que relacionan la incidencia de la pandemia con factores sociodemográficos, como el envejecimiento o el sobreenvejecimiento; del que en la Universidad de Málaga se ocupa analizar la importancia de los focos de contagio vecinal desde el inicio de la pandemia y el modo de abordar su detección y delimitación (Perles et al., 2021); del que, en la Universidad Rovira i Virgili, ha desarrollado un modelo que incorpora los datos de los efectos de la pandemia en el conjunto del país, relacionándolos con datos demográficos y de movilidad entre municipios; del que ha desarrollado la herramienta "El COVID-19 por municipios" en la Universidad de Girona, que permite consultar el estado del virus en cada municipio de Cataluña; del grupo GEOTER que, en la Universidad de Burgos, ha analizado la situación en Castilla y León; del GIR PANGEA de Valladolid, que, también para Castilla y León, hace una interpretación cartográfica plasmada en un atlas-diario de la epidemia; o del que, desde el Laboratorio de Humanidades Digitales la Universidad de Navarra, ha puesto en marcha un portal web con información referente a la pandemia en el territorio de la Comunidad Foral de Navarra 
Los objetivos concretos de este trabajo, a partir de un análisis exhaustivo de cómo evolucionó la pandemia en Asturias a lo largo de los primeros 360 días, en el que se ha centrado la atención en su incidencia en el conjunto de la población asturiana y específicamente en el tramo de población de 65 años y más.

Por un lado, se ha tratado de determinar el comportamiento de la pandemia a lo largo del tiempo en lo tocante a la distribución territorial, realizando un análisis a escala municipal, y de relacionar los resultados obtenidos con los contrastes existentes, en términos sociales, económicos y territoriales, entre el área metropolitana del centro de la región, en la que, en un 10\% del territorio, se concentra casi el $90 \%$ de la población regional y buena parte de la actividad económica y de la prestación de bienes y servicios, y un espacio rural en el que, aunque en términos desiguales, se concentran los problemas de envejecimiento, despoblación, déficit de equipamientos y servicios, etc.

A modo de hipótesis de partida consideramos que, dado que el virus se transmite fundamentalmente por vía respiratoria, las zonas con mayor densidad de población parecen ser las más proclives para que en ellas se dé la transmisión. Por otro lado, las características del poblamiento también tienen relevancia, pues, independientemente de la densidad, en aquellos municipios donde la población se ubica en núcleos de tamaño medio y grande se produce con mayor facilidad la propagación descontrolada. Por último, la concentración en algunos municipios de las actividades industriales, comerciales y de servicios, que, al tiempo, actúan como cabeceras regionales o comarcales para la prestación de servicios y que concentran las áreas de ocio y de comercio, constituye otras de las variables a considerar.

Por otro lado, nos marcamos el objetivo de comprobar la posible existencia de algún tipo de correlación entre las variables envejecimiento, número de casos y letalidad, comprobando si los municipios más envejecidos se correspondían, en términos relativos, con los que contaban con un mayor número de casos y de fallecidos.

Del mismo modo, se orientó la investigación hacia la resolución de la incógnita de si la presencia de residencias de la tercera edad, donde se da una concentración de personas mayores, en un espacio reducido y, por tanto, con mayores posibilidades de propagación del virus una vez producido el contagio, podía contribuir a la explicación del desigual grado de incidencia de la pandemia en el territorio asturiano.

En definitiva, nuestro objetivo ha sido analizar cómo se ha distribuido la enfermedad en Asturias a lo largo de casi un año, tratando de examinar y señalar las diferencias intermunicipales y en 
qué medida estas pueden estar justificadas en desequilibrios territoriales en cuanto a las características sociodemográficas de Asturias.

\section{Fuentes y método}

\subsection{Las fuentes}

La pandemia de COVID-19, enfermedad causada por el coronavirus SARS-CoV-2, ha propiciado la existencia de un gran número de entidades, públicas y privadas, que ofrecen datos acerca de la evolución de la misma; unos datos en constante proceso de actualización, y que son presentados en forma de gráficos interactivos (o tablas) en unos casos, de mapas interactivos o no interactivos, o simplemente en ficheros descargables.

Para la elaboración del presente artículo se han revisado los datos existentes en diversas fuentes oficiales, es decir, datos relativos al número de casos y al número de fallecidos proporcionados por las fuentes oficiales autonómicas y nacionales, a partir de los cuales es posible realizar los cálculos oportunos, según requiera el análisis que se realice.

Se han revisado los datos proporcionados por el Gobierno de España (https://www.mscbs.gob.es/), así como los facilitados por el Gobierno del Principado de Asturias y por distintos organismos o instituciones dependientes o relacionadas con la Consejería de Salud.

A modo de ente aglutinador, el Gobierno del Principado de Asturias ha habilitado el "Portal Coronavirus COVID-19 del Principado de Asturias" (https://coronavirus.asturias.es/inicio), donde se recopila una gran cantidad de información (medidas, recomendaciones, noticias, datos, etc.), junto con enlaces a los datos proporcionados por AsturSalud (Portal de Salud del Principado de Asturias) y por el Observatorio de Salud en Asturias (OBSA).

El Observatorio de Salud en Asturias tiene asignado el cometido de dar a conocer la situación de salud en Asturias, de facilitar dicha información a tantos agentes de salud como sea posible, y de relacionar los datos de salud con las medidas sanitarias implantadas en el Principado.

Creado en el año 2010, su ámbito de estudio son los municipios de Asturias y sus áreas sanitarias, habiendo comenzado su labor de recogida de datos acerca de la COVID-19 el día 29 de febrero de 2020, día del primer contagio registrado en Asturias.

EI OBSA facilita información desglosada y descargable, generada desde su propia base de datos, donde se recoge "información reportada por 4 fuentes: vigilancia epidemiológica, 
SESPA, descargas de laboratorios y GO.DATA" (https://obsaludasturias.com/obsa/nivelescovid-19/).

A través del OBSA se puede obtener, en detalle y desde el principio de la pandemia, información descargable relativa a multitud de variables relacionadas con la COVID-19. En particular se puede acceder a más de 100 variables desglosadas a nivel regional, área sanitaria y municipio relativas a los casos, las pruebas, las incidencias, los fallecidos, las hospitalizaciones, etc. $^{1}$

Una vez analizadas las fuentes, hemos constado que hay variables que se repiten y otras que difieren, y también que para una misma variable existen divergencias en los datos, algunas veces notables. En razón de esto, hemos optado por utilizar dos fuentes de información en función de la escala de análisis, teniendo en cuenta que ambas proporcionan desglose diario de los datos desde el inicio de la pandemia.

Para enmarcar el análisis de la evolución temporal de la pandemia en Asturias, comparándola con la de España, hemos recurrido a los datos ofrecidos por el Centro Nacional de Epidemiología. Concretamente se han utilizado los disponibles en la web "COVID-19 en España", dentro de la sección "PANEL COVID-19", en el apartado "Documentación y datos" (https://cnecovid.isciii.es/covid19/\#documentaci\%C3\%B3n-y-datos), descargando la información contenida en el archivo "casos_hosp_uci_def_sexo_edad_provres.csv", que permite conocer el desglose provincial de los datos, tanto de casos como de fallecidos diarios, y que posibilita, por agregación, calcular el dato total para España.

Por su parte, para realizar el análisis detallado de la situación y de la evolución de la COVID-19 en Asturias y sus municipios hemos utilizado la información facilitada por el Observatorio de Salud de Asturias disponible en el apartado "Situación de salud, Niveles de alerta COVID 19", sección Datos, de donde se ha descargado la información para el conjunto de la región y para cada uno de los municipios.

Nos hemos centrado en el análisis de dos variables que consideramos básicas, como son los casos diagnosticados y los datos de fallecidos. Pero mientras para el conjunto del país solo se han utilizado los datos totales, dado que el objetivo era realizar un encuadre general, para Asturias y sus municipios se ha recurrido también a la información desagregada para la

1 Acceso a la información en la web: https://obsaludasturias.com/obsa/ $\rightarrow$ Situación de salud $\rightarrow$ Niveles de alerta covid $\rightarrow$ Datos 
población mayor de 65 años, algo muy relevante si tenemos en cuenta la especial incidencia que ha tenido el virus en ese tramo de edad, sobre todo en lo que se refiere a la tasa de letalidad.

\subsection{El método}

A partir de los datos obtenidos se ha calculado la incidencia ( $\frac{\text { número de casos de COVID-19 notificados }}{100000 \text { habitantes }} y \frac{\text { número de fallecidos por COVID-19 }}{100000 \text { habitantes }}$ ), tanto para el total como para el grupo de edad de 65 y más años, utilizando como población de referencia la proporcionada por INE a partir del Padrón a 1 de enero de 2020. Además, hemos calculado la letalidad ( $\left.\frac{\text { número de fallecidos por CoviD-19 }}{\text { casos de COVID-19 diagnosticados }}\right) \times 100$, igualmente desagregada para los mayores de 65 años. Para los casos y los fallecidos se ha realizado tanto el cálculo diario como el acumulado, para la letalidad tan solo el acumulado.

Las variables seleccionadas, puestas en el contexto territorial, nos han permitido abordar el análisis de cuáles han sido las peculiaridades de la pandemia en cada municipio, y estudiar con especial atención los que han presentado mayores incidencias.

A través de este análisis de base territorial, hemos pretendido indagar acerca de las posibles relaciones existentes entre la incidencia y los desequilibrios territoriales, poniendo el foco en la estructura del poblamiento, la densidad de población, el envejecimiento o la propia estructura territorial de cada uno de los conejos asturianos, con el fin de obtener pautas que expliquen la desigual incidencia del virus en el territorio y sus dispares valores espaciales en lo que a mortalidad se refiere.

El análisis de la evolución temporal de la pandemia ha sido objeto de una revisión minuciosa. Al igual que ha ocurrido con otras pandemias a lo largo de la historia, en el desarrollo de la COVID-19 hemos podido comprobar cómo la expansión se produce en fases denominadas olas, algunas de ellas estacionales y otras directamente vinculadas con la transmisión por hábitos sociales. En razón de esto, hemos realizado un estudio día a día de la influencia de la pandemia en los 78 municipios asturianos desde el 29 de febrero de 2020 hasta el 22 de febrero de 2021, es decir 360 días, lo que nos ha llevado a realizar una organización de los datos para obtener la secuencia temporal cuyo resultado ha sido una geodatabase con 28440 registros, que incluye información diaria de cada uno de los 78 municipios asturianos y del total regional, con datos relativos al total de casos diagnosticados, al de casos diagnosticados en personas de 65 y más años, al de fallecidos totales y al de fallecidos de 65 y más años. 
A partir de esos datos iniciales hemos calculado las tasas de incidencia por cada 100000 habitantes, diaria y acumulada, tanto totales como referidas a los mayores de 65 años, así como la tasa diaria acumulada de letalidad para ambos grupos. Un análisis se ha realizado para cada uno de los 360 días del periodo analizado.

La plasmación gráfica de este análisis, en lo que a distribución geográfica del fenómeno se refiere, son los seis mapas básicos que se incluyen en el artículo (figuras 8, 11 y 12), así como los 72 mapas con el resumen mensual de las variables analizadas, de los cuales 48 se han incorporado al texto (figuras 6, 7, 9 y 10) mientras que tanto estos como el resto se han convertido en cartografía animada empleando la herramienta Timer Slider de Arcmap, de manera que es posible visualizar de forma sencilla cuál ha sido la evolución de la pandemia diariamente y por municipios a lo largo de casi un año.

Para que el lector pueda acceder a esta cartografía se han empleado dos procedimientos. Por un lado, la cartografía animada se ha convertido a formato de vídeo para las siguientes variables: total mensual de casos diagnosticados, total mensual acumulado de casos diagnosticados, total mensual de casos en mayores de 65 años, total mensual acumulado de casos en mayores de 65 años, total mensual de fallecidos, total mensual acumulado de fallecidos, total mensual de fallecidos mayores de 65 años, total mensual acumulado de fallecidos mayores de 65 años, letalidad mensual y letalidad mensual en mayores de 65 años (Herrera, 2021a-j).

Por otro lado, se han incluido en este artículo recursos de Realidad Aumentada que permiten visualizar la información y que ayudan a comprender con mayor precisión cuál ha sido la evolución temporal y espacial del virus en Asturias. ${ }^{2}$

Tales recursos de Realidad Aumentada consisten en la conversión de los mapas del artículo, que

incluyen el logo , en "marcadores de imagen", de manera que el uso de la aplicación desarrollada para dispositivos móviles permite que situando el dispositivo sobre la imagen, una vez activada la aplicación, sea posible visualizar el mapa animado en el que se recogen los miles de registros de la geodatabase. Para acceder a la aplicación se puede utilizar el link https://studio.onirix.com/exp/36M8GL o el siguiente código QR:

2 Los recursos de Realidad Aumentada se han elaborado en el marco del proyecto de I+D+i "La Realidad Aumentada como herramienta para la explicación del paisaje" (CSO2017- 84623-R). 


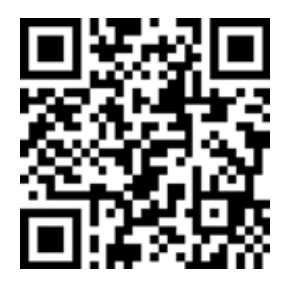

\section{Resultados}

\subsection{La evolución espacio-temporal de la COVID en Asturias. Estudio comparado con la evolución en España (marzo de 2020-febrero de 2021)}

Hemos considerado oportuno, antes de entrar en el análisis a escala regional, realizar un encuadre general de la evolución de la pandemia a lo largo del periodo de 360 días (entre el 29 de febrero de 2020 y el 22 de febrero de 2021) comparando lo sucedido en Asturias con la evolución general de España. Para ello, a partir de la información del CNE-ISCIII se ha calculado la incidencia diaria, por cada 100000 habitantes, en ambos territorios, tanto para los casos como para los fallecidos.

A lo largo del periodo analizado, el comportamiento de la incidencia diaria ha sido, en rasgos generales, similar en Asturias y en España, si bien con algunos aspectos diferentes tanto en la intensidad como en la duración de cada ola (Figura 1). La incidencia acumulada global para Asturias fue de 4195,2, cifra más baja que la de España, que alcanzó los 6529,5 casos por cada 100000 habitantes. Por su parte, los valores extremos oscilan entre los 0 casos, que Asturias registró en varios días del periodo analizado, y los 80 de incidencia máxima en Asturias a mediados de noviembre de 2020, y los 90 de España a mediados de enero de 2021. Por otro lado, la evolución de los datos muestra tres olas, con una primera individualizada y distanciada en el tiempo de la segunda y la tercera, que tienen valores muy superiores a la primera y que, además, se encadenan sin periodo de descanso.

En la primera ola Asturias solo presenta 3 días por encima de 10 casos por cada 100000 habitantes, mientras que España supera este umbral 20 días, 3 de ellos con valores superiores a 20. 
Figura 1.Incidencia diaria de casos notificados

\section{de COVID-19 por cada 100000 habitantes en Asturias y España}

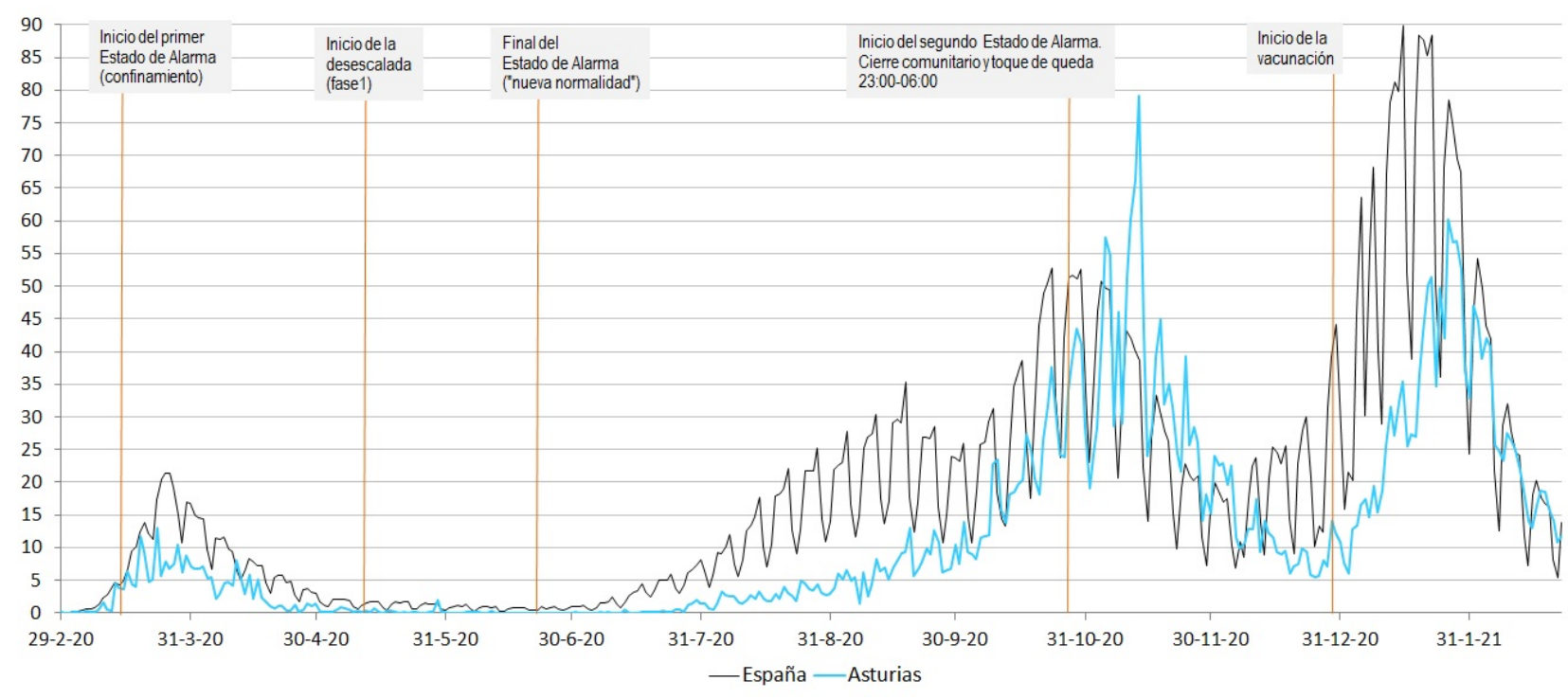

Fuente: elaboración propia a partir de los datos de casos

CNE-ISCIII (2021) y los datos de población (INE, 2020)

La transición entre la primera y la segunda ola presenta similitudes en los dos ámbitos territoriales: una bajada prolongada y significativa del número de casos, que en Asturias es mayor, pues en el periodo del 16 de mayo al 16 de julio contó con 42 días sin ningún positivo, 19 de ellos seguidos, y con una incidencia acumulada de 5,7 casos por cada 100000 habitantes, mientras que España, en ese mismo periodo, arrojaba un dato de 65,2 de incidencia acumulada y con algún caso todos los días. Por otro lado, España contó con valores superiores a una incidencia de 10 de forma continua a partir de mediados de agosto, mientras que Asturias no empezó a sobrepasar este umbral de forma continua hasta primeros de octubre.

La consecuencia de este proceso fue que el inicio de la segunda ola difiriera sustancialmente entre ambos territorios y su perfil fuera distinto. En España comenzó a partir de la segunda mitad de julio, con un crecimiento lento y progresivo, y se prolongó hasta mediados de diciembre de 2020; una fase larga que incluyó una ligera bajada a finales de septiembre y que alcanzó los valores más altos a finales de octubre de 2020. En el caso de Asturias, su segunda ola se iniciaba en septiembre y duraría hasta la segunda quincena de diciembre, alcanzado los valores más altos en la primera quincena de noviembre; lo que supone un retraso, especialmente en su inicio, pero también en su pico y descenso, con respecto al global nacional. A nivel regional se superó el umbral de los 50 casos por cada 100000 habitantes en 6 días, 3 de ellos por encima 
de 60, con el pico en casi 80; a nivel nacional ese umbral se sobrepasó 7 días, llegando a un máximo de 52,8 por cada 100000 habitantes.

A diferencia de la segunda ola, la tercera arrancaba con unos valores relativamente altos, puesto que apenas si se había logrado bajar unos pocos días por debajo del umbral de 10 casos por cada 100000 habitantes. En España esta circunstancia se dio en algunos días concretos durante la primera quincena de diciembre de 2020, mientras que Asturias encadenaba 13 días por debajo de ese umbral en la segunda mitad de ese mes. El desarrollo de la tercera ola fue muy rápido en España, alcanzando valores por encima de 50 a lo largo de 19 días durante enero y de febrero de 2021, siendo 11 de ellos superiores a 70 y, de estos, 6 por encima de 80, con el valor máximo rozando los 90. En Asturias el umbral de 50 casos por cada 100000 habitantes solo se superó 6 días en la segunda mitad de enero de 2021, siendo su máximo ligeramente superior a 60. Si bien en Asturias el ascenso de esta tercera ola se retrasó con respecto a España, en ambos territorios se dio un comportamiento similar en el descenso, con valores inferiores a 20 a partir de mediados de febrero de 2021.

Por lo que respecta a la evolución temporal de los fallecimientos en Asturias y en España, si bien presentan unos rasgos generales similares, con 3 olas, al igual que los casos, en fechas parecidas, se pueden apreciar diferencias significativas en cuanto a la intensidad (Figura 2). La incidencia acumulada global de fallecimientos para Asturias fue de 170,1 casos por cada 100000 habitantes, cifra más alta que la de España, que alcanzó los 146,2. Los valores extremos oscilaron entre los 0 casos, que, en España y especialmente en Asturias, se registraron en varios días del periodo analizado, y los 1,9 de máximo de España en marzo de 2020 y los 3 de incidencia máxima en Asturias en la segunda mitad de noviembre de 2020. Al igual que en los casos, la evolución de los datos muestra una primera ola individualizada y distanciada en el tiempo de la segunda y la tercera, que se encadenan sin apenas periodo de descanso.

La primera ola se desarrolló entre mediados de marzo y finales de abril de 2020, con un crecimiento muy rápido en España, que mantuvo valores superiores a 1 a lo largo de 28 días consecutivos, llegando a rozar los 2 fallecidos por cada 100000 habitantes, y con un descenso lento hasta llegar a valores próximos a 0 en junio; mientras que en Asturias no se percibe una ola tan bien definida, alternando valores por encima de 1 (el máximo es 1,7) con días de muy baja incidencia, o incluso 0 . 
Figura 2. Incidencia diaria de fallecimientos

por cada 100000 habitantes en Asturias y en España

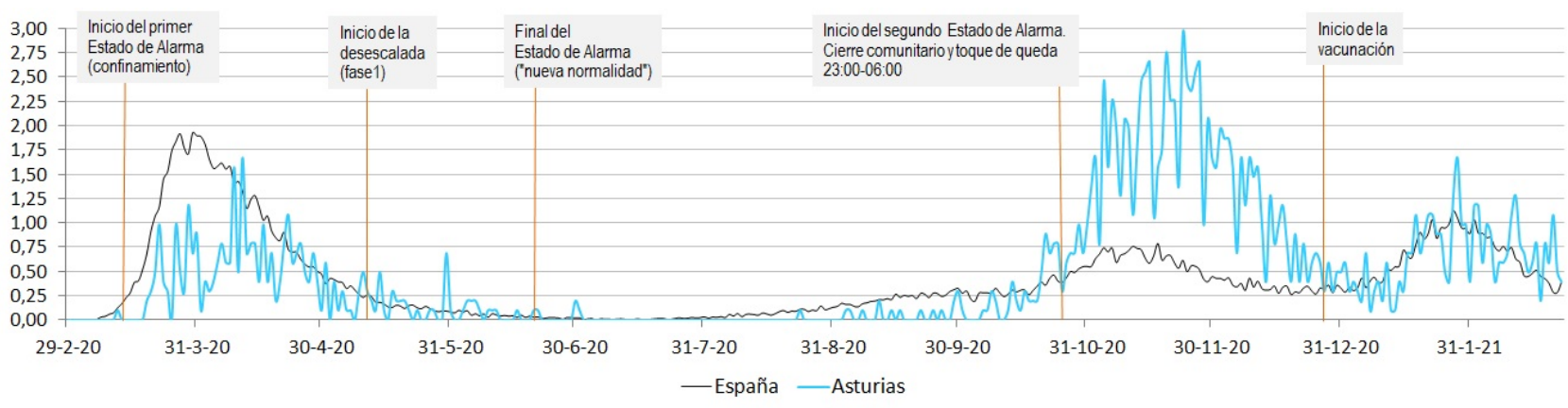

Fuente: elaboración propia a partir de los datos de casos

CNE-ISCIII (2021) y los datos de población (INE, 2020)

La transición entre la primera y la segunda ola se prolongó a lo largo de varias semanas desde mayo a hasta finales de julio de 2020, tanto en el caso de España como en el de Asturias. A partir de ese momento, un rápido proceso de desescalada y la retirada de medidas de control en el ocio propiciaron el inicio de un ligero repunte, que se prolongaría hasta mediados de octubre, caracterizado por un incremento ligero, pero continuado, de la curva en el caso del conjunto del país, en contraste con un crecimiento en dientes de sierra en el caso asturiano.

En la segunda ola las diferencias entes Asturias y España son muy significativas. En el conjunto del país su parte álgida se desarrolló desde mediados de octubre hasta mediados de diciembre de 2020 y tuvo un desarrollo más contenido que la primera, sin llegar a alcanzar el umbral de 1 (el máximo es 0,8 ). Por el contrario, en Asturias fue más prolongada, de mediados de octubre a la primera quincena de enero de 2021, presentando, además, los peores datos de todo el periodo; en 40 días se registraron valores superiores a un fallecido diario por cada 100000 habitantes, y, dentro de ellos, en 15 se superaron los 2, llegando a rozar 3 como nivel máximo.

Aunque en ambos territorios el tránsito de la segunda a la tercera ola presenta un perfil parecido, con un descenso del número de fallecidos, todos los días se registró en ambos casos alguna muerte. La tercera ola se desarrolló desde enero hasta finales de febrero de 2021 siendo su máximo de 1,1 fallecidos por cada 100000 habitantes en España y de 1,7 en Asturias, con 3 días por encima de 1 a nivel nacional y 10 días en Asturias.

Para centrar el análisis en Asturias hemos considerado diversos aspectos para conocer con cierto detalle la evolución temporal y territorial de la pandemia. Partiendo de los datos obtenidos del OBSA, se ha considerado la población total y el grupo de edad de 65 y más años, especialmente afectado por la covid-19, prestado atención tanto a los datos absolutos como las 
incidencias por cada 100000 habitantes. Una evolución que, en términos comparativos entre la población total y el grupo de edad de 65 y más años, queda reflejada en las figuras 3 y 4.

Según el OBSA, hasta el 22 de febrero de 2021 se contabilizaban en términos globales un total de 42717 casos en Asturias, pero su distribución temporal se produjo, como ya se ha apuntado, en distintas fases (Figura 3). En la primera ola, durante los meses de marzo y abril de 2020, se registraron 2329 casos, un 5,5\% del total. Los meses posteriores fueron de muy baja incidencia, registrándose en mayo, junio y julio únicamente 201 casos, el 0,5\% del total, y de agosto a septiembre, periodo en el que se experimentó cierto aumento, 2978 positivos, un 7\%, cifra levemente superior a la primera ola. La segunda ola, de octubre a diciembre de 2020, es el periodo que concentró el mayor número de casos, 21772 , la mitad del total. En la tercera ola, entre enero y febrero de 2021, se alcanzaron los 15437 casos, el 36,1\% del total.

Si comparamos estos datos con los disponibles correspondientes a la gripe de 1918 (Fernández et al., 2019), vemos algunas similitudes, pero también muchas diferencias. Al igual que en aquella ocasión, Asturias ha experimentado tres olas (en el periodo analizado), en ambas pandemias la segunda ola fue con mucho la más agresiva. Pero más allá de esa coincidencia, las condiciones sociosanitarias y la propia configuración territorial y social de Asturias dejan pocas opciones a la comparación; la realidad social y demográfica asturiana actual poco tiene que ver con la de 1918 y, además, las propias características del virus de la gripe y de la COVID-19 también introducen particularidades claras.

Si nos atenemos a la distribución según los dos grupos de edad considerados, del total de casos, 31419 fueron de menores de 65 años y 11298 de 65 años o más, lo que viene a mostrar que el 26,4\% de los positivos fue gente mayor, pudiendo apreciarse una coincidencia en el valor de la población de este grupo de edad, que representa el 26,2\% del total. Sin embargo, vistas conjuntamente la evolución del número de casos y de la incidencia diaria por cada 100000 habitantes (Figura 3) se pueden apreciar las variaciones experimentadas según la afección a la población mayor, que tiene una presencia continuada dentro de los casos, pero con diferencias en la cantidad y en la proporción que representan sobre el total de positivos en cada fase. 


\section{Figura 3. Evolución del número diario y de la incidencia diaria de casos en Asturias}
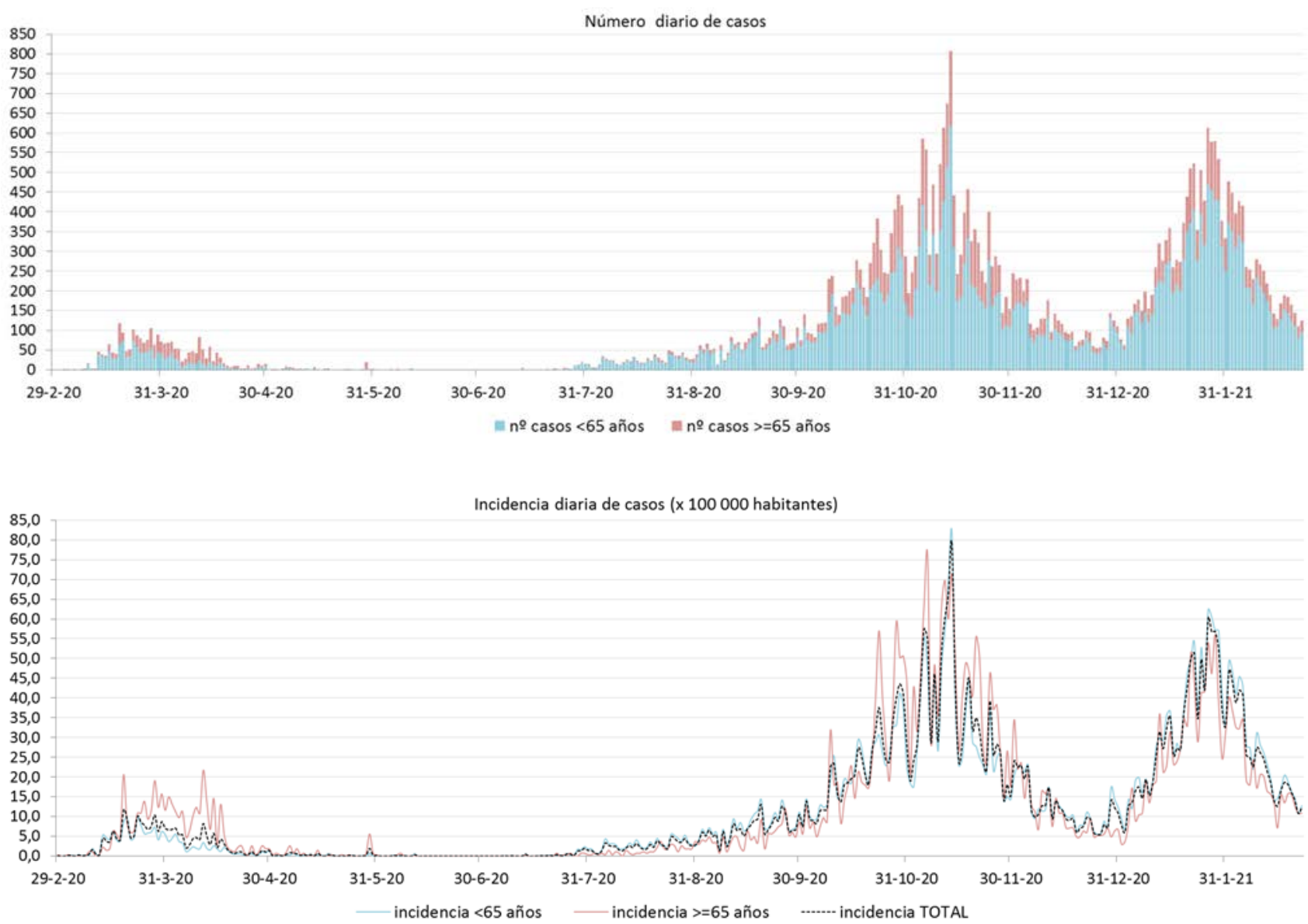

Fuente: elaboración propia a partir de los datos de casos

OBSA (2021) y los datos de población (INE, 2020)

En la primera ola los mayores representaron casi la mitad de los casos, sumando el 44,4\% de los positivos en esos meses; un valor que se ve reflejado en la incidencia diaria: los valores más altos de Asturias se movieron entre 5 y 10 casos por cada 100000 habitantes, con un máximo de 11,7, mientras que en la población de 65 y más años la incidencia se movió entre 10 y 20, llegando a 21,8 de valor máximo. En ese mismo periodo los valores para la población menor de 65 años no alcanzaron el 10, fijándose el máximo en 9,8.

Durante el periodo de muy bajo número casos, de mayo a julio de 2020, la proporción de contagios en personas mayores descendió y pasaron a suponer un tercio de los casos. Esta tendencia continuó en agosto y septiembre, cuando las personas mayores solo aportaron una sexta parte de los casos registrados. En la segunda y tercera olas se incrementó la proporción de los mayores de 65 años, el 28,7\% en la segunda ola, y 22,3\% en la tercera, situándose en valores próximos a la proporción de la población mayor respecto a la población total; pero, a diferencia de la primera fase, la incidencia diaria fue mucho más parecido a en los dos grupos 
de edad y en el total, y el nivel máximo lo marcó la población menor de 65 años, con 82,0 casos por cada 100000 habitantes en la segunda ola y 62,3 en la tercera.

La evolución del número de personas fallecidas diariamente, analizada globalmente y según los dos grandes grupos de edad analizados, muestra algunas similitudes, como es un perfil general similar, con tres olas y un periodo amplio de baja incidencia entre la primera y la segunda, mientras que la tercera ola se encadenaba con la segunda sin periodo de transición (Figura 4).

El aspecto más reseñable es, sin duda, el gran peso de la población mayor de 65 años entre los fallecidos; de hecho, de las 1733 muertes registradas en Asturias en todo el periodo analizado, 1633, el 94,3\%, se produjeron en personas de 65 y más años, una proporción que se mantuvo en todas las fases de la pandemia. En cuanto al número de fallecimientos, en la primera ola se registró el 15,3\% de las muertes, la segunda ola, al igual que ocurría con el número de casos, es la que más número de fallecimientos concentró, 1017, el 58,7\% del total; la tercera supuso el $20,7 \%$.

Atendiendo a la distribución según los dos grupos de edad, el gran peso de los fallecidos mayores hace que sus valores sean muy similares, tanto en número como en porcentaje, a los de los casos totales. En este sentido cabe señalar el reparto temporal en los menores de 65 años, puesto que el $64 \%$ de estos fallecidos de este grupo de edad se produjo en la segunda ola.

En cuanto a la incidencia diaria de fallecidos, el comportamiento del total y de los dos grupos de edad está bien diferenciado en cuanto a valores alcanzados. Si bien la silueta global es paralela a la de los mayores de 65 años, el valor más alto siempre corresponde a las personas de 65 y más años. En la primera ola la incidencia diaria máxima fue de 6,4 fallecidos por cada 100000 habitantes, mientras que la global se situaba en el 1,7 y la de menores de 65 años solo en el 0,3. Durante la segunda ola la población mayor superó varios días una incidencia de 9 fallecidos por cada 100000 habitantes, con un máximo en 9,8, que supuso 26 personas fallecidas en un día; por contra la global de Asturias se quedaba en 2,9 y la de menores de 65 en 0,5. La tercera ola, al igual que la primera, presenta unos valores más bajos, con 5,6 de incidencia máxima para los mayores de 65 años, 1,7 para el total y 0,3 para los menores de 65 años. 
Figura 4. Evolución del número diario y de la incidencia diaria de fallecidos en Asturias
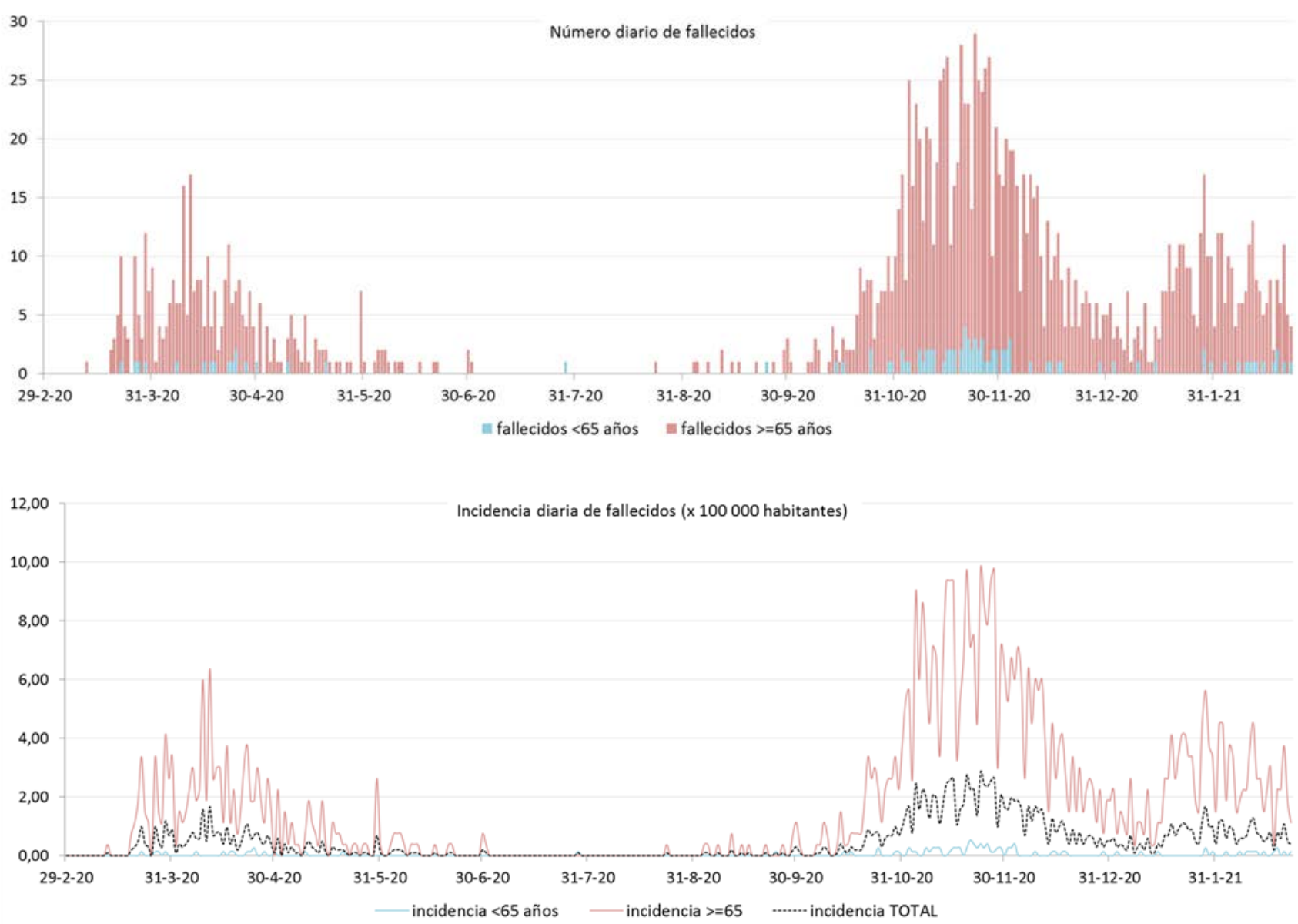

Fuente: elaboración propia a partir de los datos de casos

OBSA (2021) y los datos de población (INE, 2020)

Una tercera variable que se ha tenido en consideración en el análisis de la evolución temporal de la pandemia en Asturias, junto al número de casos y al de fallecidos, es la letalidad, es decir, el porcentaje que suponen los fallecidos sobre el número total de casos, tanto a nivel global, como para los dos grupos de edad considerados. En este caso, para ver la evolución, hemos optado por realizar un análisis diario a partir de los datos acumulados (Figura 5), dado que los fallecidos de un día no se corresponden con los casos de ese mismo día, sino con personas contagiadas varios días o semanas atrás, por lo que no es posible hacer una correlación estrictamente diaria. 


\section{Figura 5. Evolución de la letalidad acumulada diaria en Asturias}

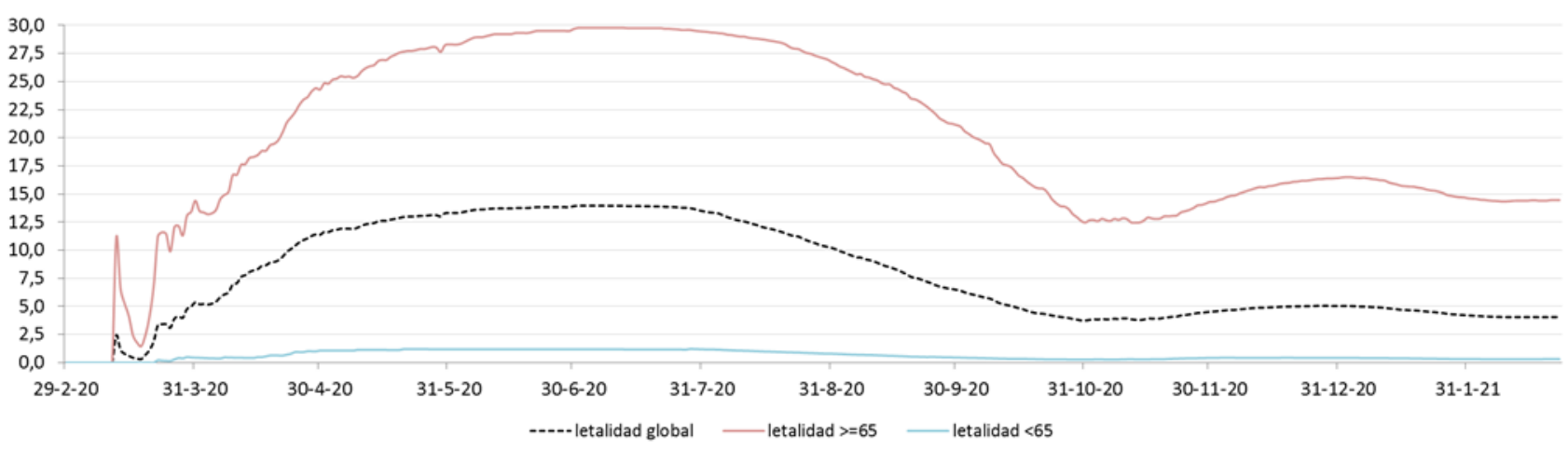

Fuente: elaboración propia a partir de los datos de casos OBSA (2021)

La letalidad total acumulada al final del periodo analizado es de un 4,1\%, es decir, de cada 100 casos detectados 4,1 fallecieron. En los mayores de 64 años esta proporción sube hasta el 14,5\%, mientras que en los menores de 65 años queda reducida a un 0,3\%. La evolución acumulada presenta los valores mayores en julio de 2020, cuando a nivel global se llega a un $14 \%$ y para los mayores de 64 años a un 29,8\%. Esto se debe a que a 31 de julio se habían alcanzado los 2530 casos, tan solo el 5,7\% del total, mientras que el número de fallecidos registrado, 341, ya suponía el 19,8\% del total computado; a partir de agosto la proporción entre número de casos registrados y fallecidos iría disminuyendo, con un ligero repunte en diciembre. La explicación de la desigualdad observada en las sucesivas fases podría ser resultado de la combinación de varias circunstancias.

De un lado hay que tener presente que en los primeros momentos la capacidad de detección de personas infectadas era muy inferior a la de los meses posteriores; durante los primeros, coincidiendo con el Estado de Alarma más severo, con un confinamiento domiciliario total de la población, ni el rastreo ni el seguimiento ni el número de PCR realizadas era comparables con los que se produjeron posteriormente, todo lo cual hace pensar que gran parte de las personas asintomáticas o con síntomas leves no fueron detectados como casos y solo los más graves fueron diagnosticados, lo cual incidiría de forma determinante para que la tasa de letalidad alcanzase unos valores singularmente elevados, al tiempo que los picos de los casos apenas sobrepasaban los 100, cuando en las olas posteriores llegarían a estar por encima de los 800 y 600 .

De otro lado, al producirse un cierre total en el primer Estado de Alarma (14 de marzo de 2020), en un momento en el en Asturias presentaba una tasa de incidencia sustancialmente 
menor que otras zonas de España, fue posible cortar la transmisión de forma drástica, hasta el punto de que en los meses posteriores la región llegaría incluso a estar libre de virus (42 días, siendo la Comunidad con más días consecutivos sin positivos -10-) coincidiendo este periodo con las medidas de desescalada que se produjeron en el conjunto del país.

De otro finalmente, para entender el repunte que se desencadenó tras el verano, hay que tener presente que los buenos datos que presentaba Asturias, unidos al cierre de los destinos turísticos exteriores, hicieron que la región se convirtiera en un reclamo para el turismo nacional. La baja incidencia durante varios meses generó una falsa sensación de seguridad, tanto entre la población local como entre la visitante, que se vio acompañada de un relajamiento de las medidas restrictiva establecidas por las distintas administraciones.

Todos estos factores contribuyen a explicar en gran medida la gran incidencia que tuvo la segunda ola en Asturias.

\subsection{La distribución territorial de la pandemia en Asturias}

Para analizar el comportamiento territorial de la pandemia en Asturias hemos recurrido a los datos agregados a nivel municipal, analizando la evolución de los mismos, al igual que en el caso de los datos globales, a lo largo del periodo comprendido entre el 29 de febrero de 2020 y el 22 de febrero de 2021. También como en el caso del análisis general, se han analizado dos variables, el número de casos y el de fallecidos, individualizando los datos para los mayores de 65 años, debido a la incidencia de la enfermedad en estos grupos de edad.

Al analizar la incidencia mensual del número total de casos diagnosticados (Figuras 6 y 7) se puede observar cómo la primera ola (marzo y abril de 2020) tuvo una escasa repercusión en la región, localizándose las mayores incidencias en los municipios de Pravia, Grado, Candamo, Castrillón y Salas, todos ellos en el sector occidental del área central de la región, con valores de más de 500 casos por cada 100000 habitantes. La segunda ola, que se inició tímidamente a finales de septiembre y alcanzó su mayor intensidad en noviembre, refleja los efectos de una relajación de las medidas de protección. La incidencia se situó en los meses de octubre y noviembre por encima de 1000 casos por cada 100000 en 18 municipios, afectando sobre todo a los de la cuenca del Nalón (especialmente a Sobrescovio y a Laviana, con incidencias que superaron los 2500 casos por cada 100000 habitantes), seguidos de Lena con más de 2300, Riosa también por encima de los 2000 casos 000. En el caso de Soto del Barco, Teverga, Bimenes y Allande, los altos valores tienen que ver con brotes que afectaron a población mayor de 65 años, coincidiendo con focos en residencias. 
Figura 6. Distribución municipal por meses del total de casos diagnosticados por cada 100000 habitantes
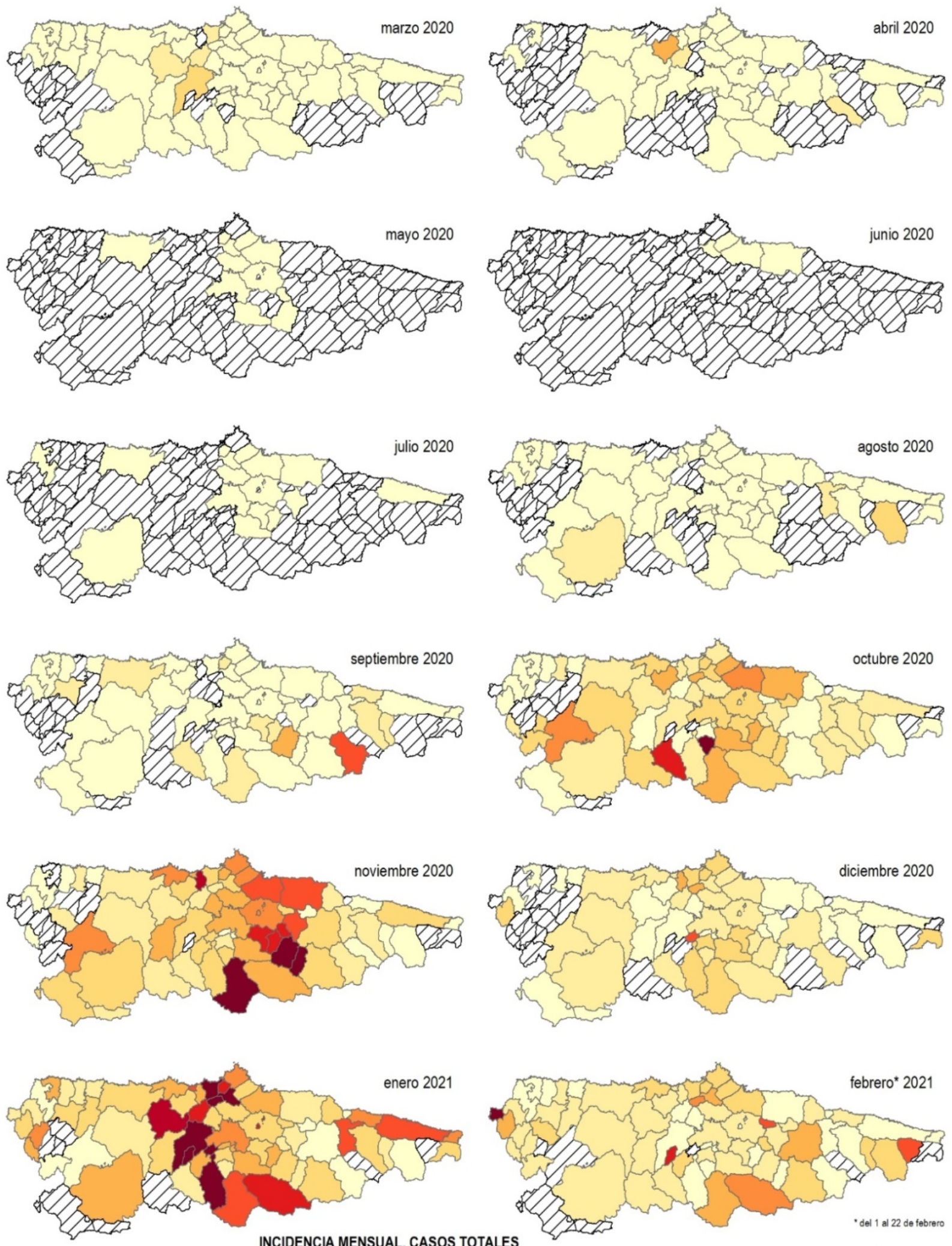

febrero* 2021
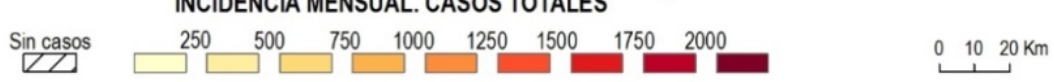

$\bigwedge^{N}$

Fuente: elaboración propia a partir de los datos

del Observatorio de la Salud de Asturias (OBSA, 2021) 
Figura 7. Distribución municipal por meses del total acumulado de casos diagnosticados por cada 100000 habitantes
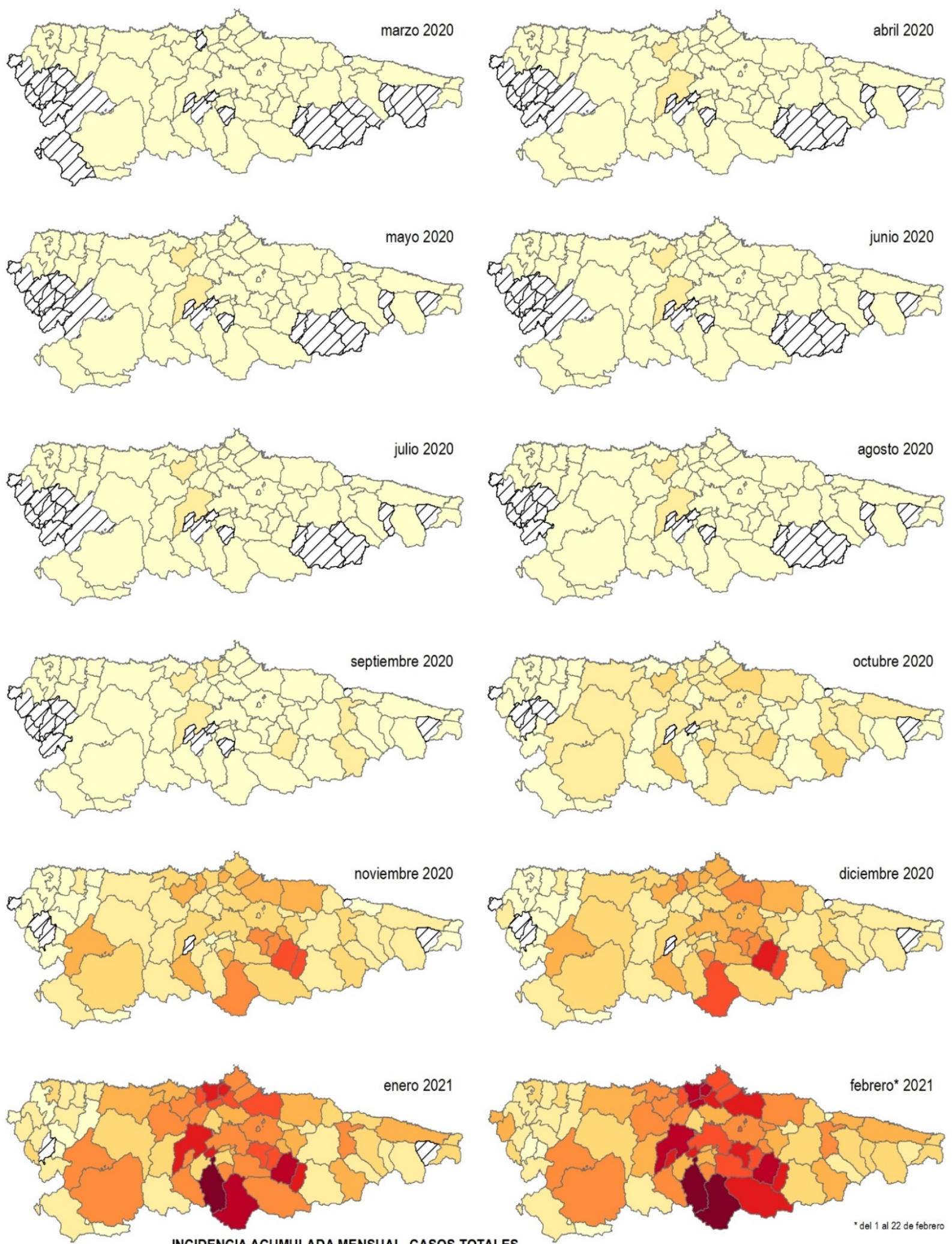

febrero* 2021

INCIDENCIA ACUMULADA MENSUAL. CASOS TOTALES
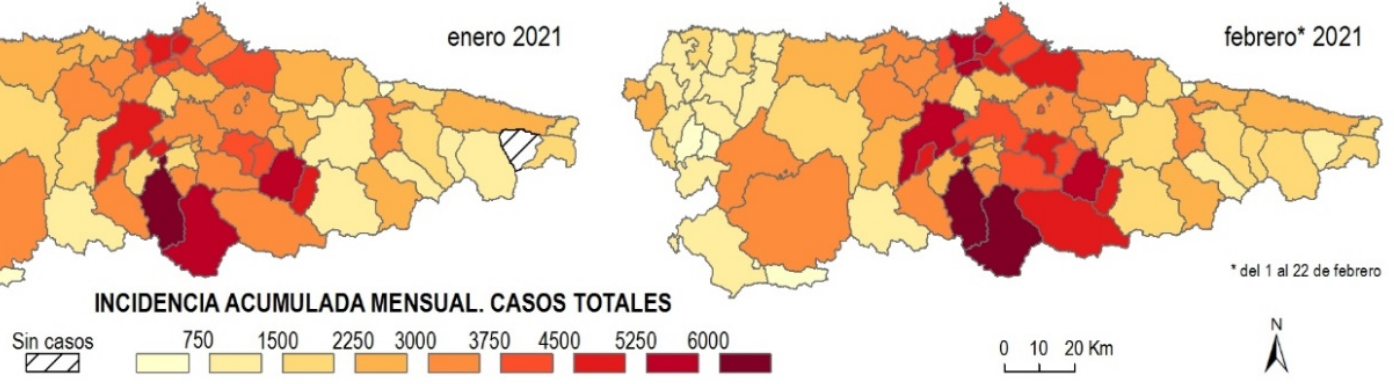

Fuente: elaboración propia a partir de los datos

del Observatorio de Salud en Asturias (OBSA, 2021) 
La tercera ola, en enero de 2021, tuvo relación nuevamente con el aumento de los desplazamientos y con la relajación en las medidas de protección durante el periodo navideño. Destacan sobremanera los valores que presenta Quirós (4717 casos por cada 100000 habitantes) vinculados al brote en una residencia de ancianos. Le siguen Grado y Yernes y Tameza con más de 3000. Por encima de los 2000 casos por 100000 están Santo Adriano, Illas, Corvera y Castrillón (en la comarca de Avilés), y San Tirso de Abres.

La incidencia acumulada mensual (Figura 7) muestra cuál fue el proceso de extensión de la enfermedad por los municipios asturianos. En la primera ola 18 municipios no registraron casos, mientras que a medida que se expandía la segunda ola del virus se producía el verdadero avance territorial, quedando tan solo 6 libres de casos. Finalmente, la tercera ola supuso la intensificación de la incidencia en los municipios de la zona central de Asturias, que coincide con mayor movilidad y densidad de población, culminando el proceso en febrero de 2021 con la expansión del virus a todos los municipios asturianos.

Si nos centramos en la incidencia acumulada de casos totales diagnosticados, que para el conjunto de Asturias se situó en 4104 casos por cada 100000 habitantes, se perciben en el análisis espacial deferencias claras entre los municipios del área central y centro-sur de la región, donde se dan los valores más altos, mientras que las zonas situadas en el interior oriental y occidental y en las "alas" del litoral han registrado una menor incidencia en términos generales.

Efectivamente, el análisis del final del proceso a escala municipal (Figura 8) pone de manifiesto que los casos en Gijón supusieron el 30,2\% de los totales, en Oviedo el 20,5\%, en Avilés el 10\%, en Siero el 4,4\%, en Langreo el 4,3\%, y en Mieres el 3,5\%; es decir, 6 municipios, los más urbanizados de la región, reúnen el 73\% del total de casos, con una correspondencia clara con la concentración de la población, que tiene unos porcentajes de distribución prácticamente iguales.

Se puede observar que son los municipios en los que se localizan las grandes ciudades, en las que a priori están presentes todos los factores de riesgo, los que presentan unos índices medios altos, solo matizables en términos relativos debido a su gran población, puesto que los valores mayores corresponden a municipios menos poblados. En relación con la incidencia de casos totales destaca Avilés, así como sus municipios limítrofes, donde las altas densidades de población parecen haber supuesto una de los condicionantes que explican su alta incidencia. 
Figura 8. Incidencia acumulada de casos totales e incidencia acumulada de casos de más de 65 años por municipios en Asturias
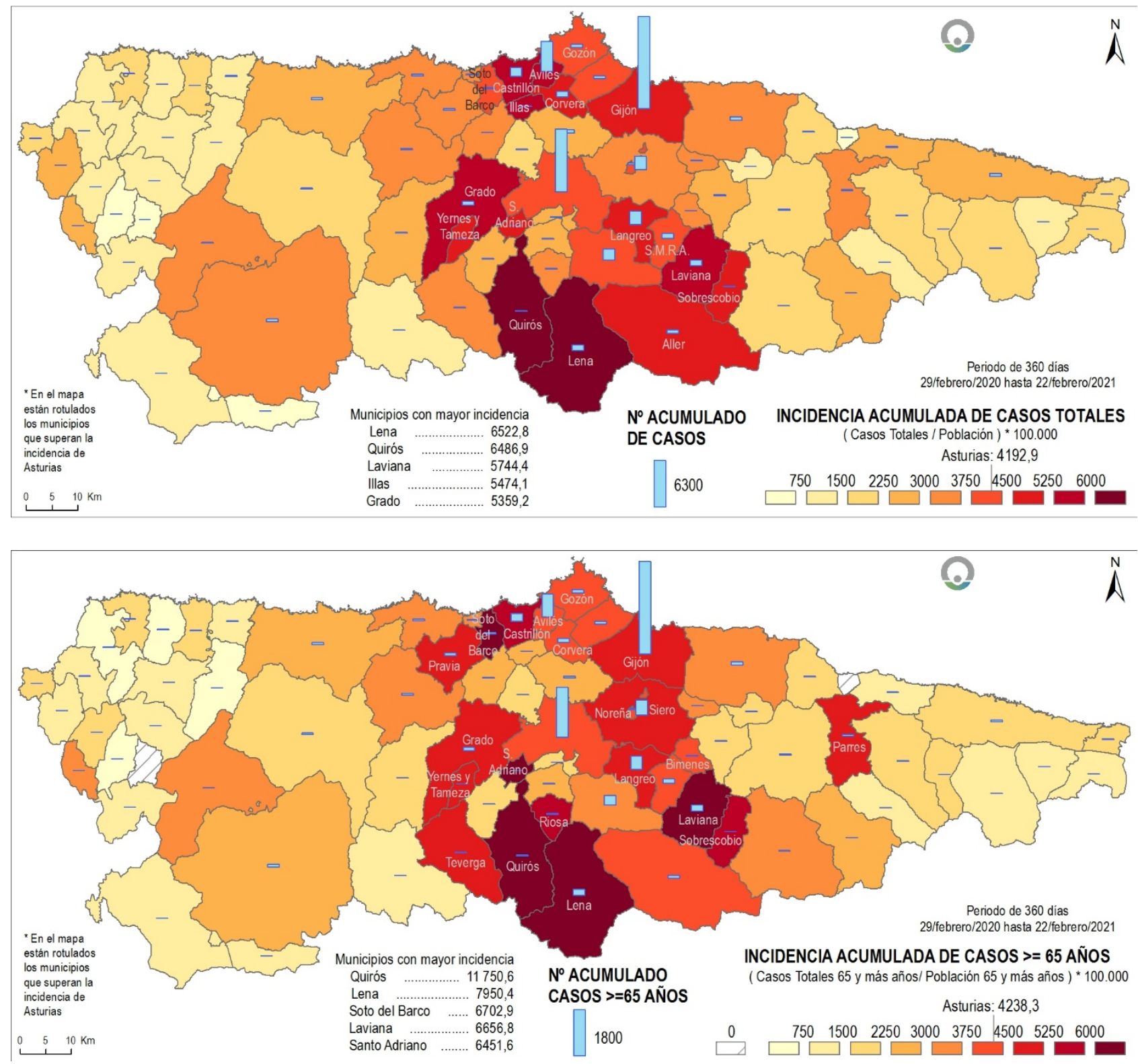

Fuente: elaboración propia a partir de los datos del Observatorio de Salud en Asturias (OBSA, 2021)

La influencia de las tres grandes ciudades y de sus entornos inmediatos sobre los municipios limítrofes se traduce, entre otros efectos, en la generación de un elevado número de desplazamientos diarios, una situación que se mantuvo incluso en los momentos de cierre perimetral de los concejos, ya que buena parte de los traslados se debían a razones laborales; por otro lado, la condición de principal foco de actividad y de prestación de servicios del área Central hace que la densidad de población presente unos valores muy elevados. 
Debido a estas circunstancias, es en la zona central de Asturias donde, en términos generales, se observan la mayor incidencia de la pandemia, con una tendencia decreciente hacia "las alas" los de la región, a excepción de Cangas del Narcea y Tineo en el sector occidental y de Parres en el oriental. No obstante, es preciso advertir que el análisis de los datos basados en la incidencia propicia algunas anomalías estadísticas, debidas al hecho de que los municipios con poca población, aun teniendo un número reducido que contagios, muestran un nivel de la incidencia muy elevado; algo que ilustran claramente casos como el de Yernes y Tameza (133 habitantes), que, con un caso registrado alcanzó una incidencia de 1503,7 (15 de enero de 2021); o el de Peñamellera Alta (498 habitantes), que con 5 casos presentaba una incidencia de 1004 (18 de febrero de 2021). Una anomalía que es aún más marcada cuando el análisis se centra en el grupo de edad de 65 y más años, ya que en este caso nos movemos en muestras aún más reducidas.

Estas anomalías estadísticas, añadidas a la existencia de variables difíciles de precisar que inciden transmisión de la enfermedad, como las relativas a los fenómenos de transmisión comunitaria, en la que inciden factores sociales, económicos e incluso culturales de diverso tipo, contribuyen a dificultar la lectura espacial de la distribución de la pandemia. El análisis de la evolución mensual, plasmado en las figuras 6 y 7, permite aclarar alguna de las anomalías derivadas de la consideración de los valores totales al final del periodo.

La distribución territorial mensual del número de fallecidos (Figuras 9 y 10) sigue el mismo patrón que la del número de casos diagnosticados, como es lógico; si bien se percibe un ligero retraso temporal, dado que los fallecimientos, normalmente, se producen varias días o semanas después del contagio.

Al final del período analizado 22 municipios asturianos, ubicados en su práctica totalidad en las áreas rurales de occidente interior y de la montaña oriental, no habían registrado ningún fallecido. 
Figura 9. Distribución municipal por meses del número total de fallecidos por cada 100000 habitantes
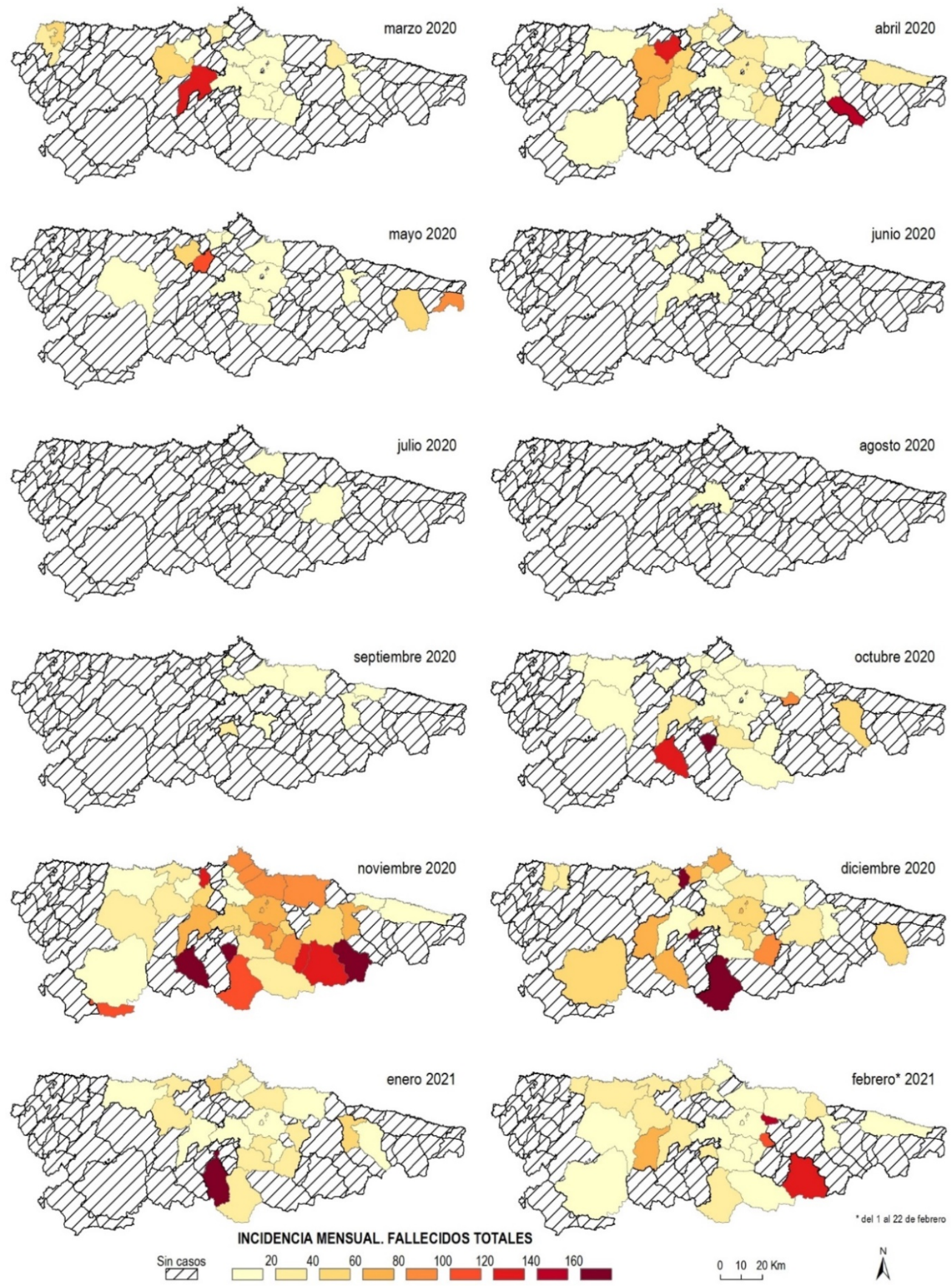

Fuente: elaboración propia a partir de los datos del Observatorio de Salud en Asturias (OBSA, 2021) 
Figura 10. Distribución municipal por meses del número total acumulado de fallecidos por cada 100000 habitantes
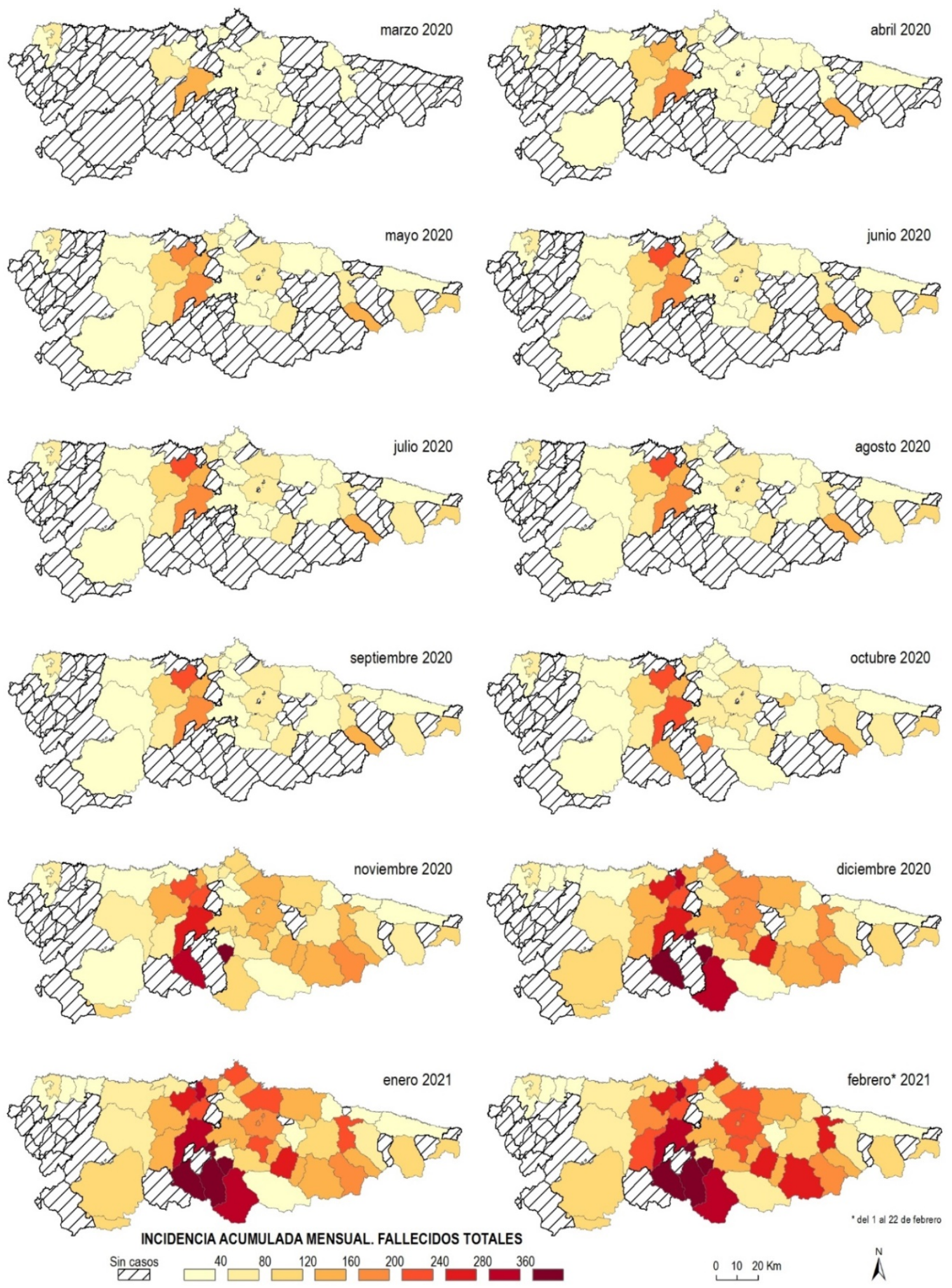

Fuente: elaboración propia a partir de los datos del Observatorio de Salud en Asturias (OBSA, 2021) 
El análisis de la distribución espacial del número de fallecidos (Figura 11) nos lleva a concluir que las causas que explican los valores de la mortalidad tienen que ver directamente con el porcentaje de población mayor de 65 años, ya que el 94\% de aquellos pertenecían a este umbral. Así, se ha comprobado la correlación entre municipios con una población envejecida, una elevada incidencia y un elevado número de decesos.

Figura 11. Incidencia acumulada del total de fallecidos e incidencia acumulada de fallecidos de más de 65 años por municipios en Asturias

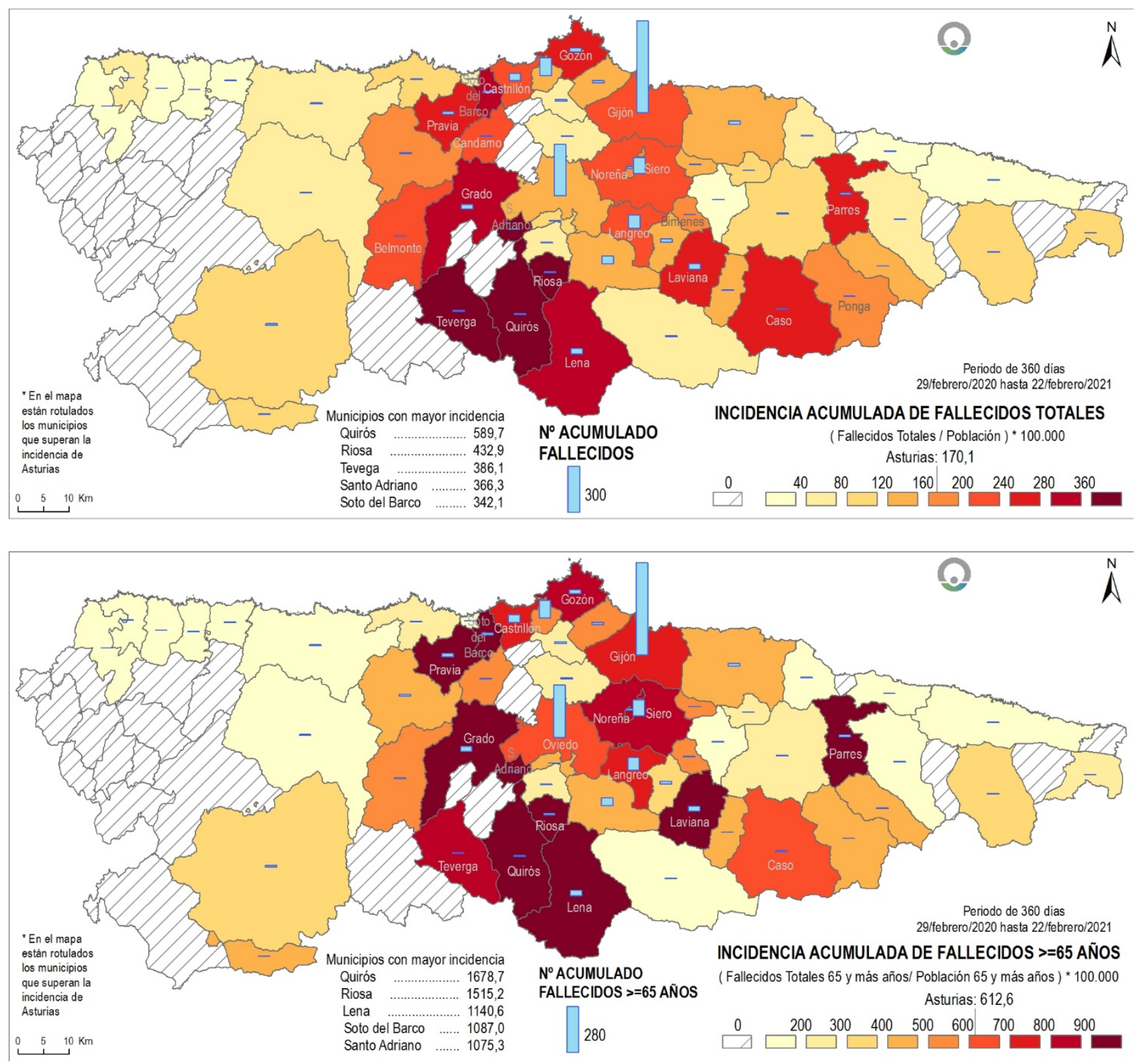

Fuente: elaboración propia a partir de los datos

del Observatorio de Salud en Asturias (OBSA, 2021) 
A todo esto habría que añadir que se ha constatado que en los municipios en los que la elevada presencia de personas mayores coincide con la localización de las residencias de ancianos, los valores de mortalidad se incrementan de forma notoria. Asturias cuenta con unas 14619 plazas en residencias de mayores (CSIC, 2021) repartidas en 58 de los 78 municipios, si bien el 56\% de las plazas se concentran en los municipios de Gijón, Oviedo y Siero. En cuanto a la incidencia acumulada de fallecidos, se sitúa en 168,9 por cada 100000 habitantes, muy lejos de las 884 que se produjeron en las principales ciudades asturianas durante la pandemia de 1918 (Fernández et al., 2019), siendo nuevamente la zona central la que registra mayores valores. De entre los municipios con mayor incidencia de fallecidos, tres cuentan con una población envejecida que supera el 30\% (Teverga 37\%, Quirós 35\%, Santo Adriano 34\%), mientras que los otros, pese a presentar valores ligeramente inferiores (Soto del Barco 29\% y Riosa 28\%), se da la circunstancia de que fueron afectados por brotes en residencias de ancianos.

La letalidad, entendida como la relación entre el número de fallecidos y el de casos totales, es la variable en la que mejor se refleja la capacidad mortífera del virus. Para su cálculo es preciso, como ya se apuntó anteriormente, recurrir a datos acumulados ya que las muertes se producen varios días después del contagio; una circunstancia a tener muy en cuenta a la hora de interpretar los datos, pues puede darse el caso de que municipios fuertemente afectados por la tercera ola presenten en los datos, y en los mapas elaborados a partir de los mismos, letalidades bajas puesto que no ha transcurrido el tiempo suficiente para contabilizar el total de fallecidos producidos en dicha ola.

En lo que respecta a la distribución espacial (Figura 12), se percibe una clara correspondencia con la incidencia acumulada del número de fallecidos del grupo de edad de mayores de 65 años, ya que, como hemos visto, el 94\% de los muertos se encuentran en este grupo de edad, lo que es reflejo a su vez de la coincidencia de los factores que explican la alta incidencia de casos y la elevada letalidad en ese grupo de población.

Si el análisis se centra en los municipios con mayor incidencia en este grupo de edad, es posible constatar la existencia de un factor que ha incidido de manera clara en un mayor número de contagios y, por tanto, en un número de fallecidos más elevado, la presencia en el municipio de una o más residencias de ancianos. La presencia del virus en zonas en las que, como es el caso de las residencias, convive población vulnerable en espacios reducidos, y donde son 
abundantes las zonas comunes, convirtió a estas en importantes focos de contagio, consecuencia de la aparición de los conocidos como "brotes en los que se producen contagios múltiples".

Figura 12. Letalidad acumulada total y letalidad acumulada de mayores de 65 años por municipios en Asturias
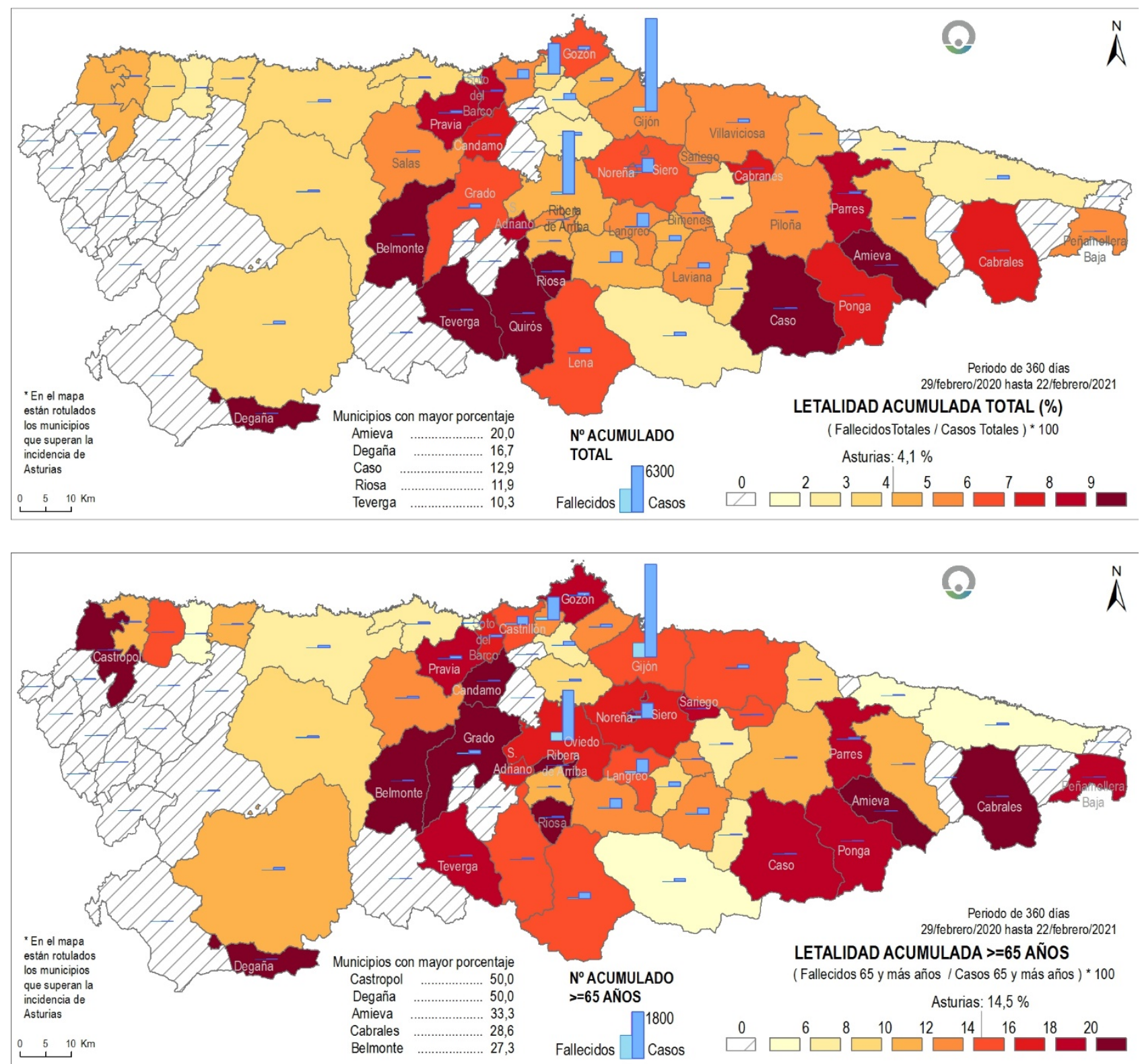

Fuente: elaboración propia a partir de los datos

del Observatorio de Salud en Asturias (OBSA, 2021)

Para constatar esta afirmación hemos utilizado los datos del OBSA (2021), que, referidos a cada una de las olas, muestran que en la primera el 66,6\% de los fallecidos se produjo en residencias, el $47 \%$ en la segunda y el $17 \%$ en la tercera, lo que supuso una letalidad del $34 \%$, $23 \%$ y $12 \%$ respectivamente. Una valoración corroborada con el análisis de los datos que 
proporciona el informe Enfermedad por coronavirus (COVID-19) en Centros Residenciales del INSERSO (CSIC, 2021). Aproximadamente el 25\% de los residentes de Asturias han sido infectados por el virus, con una letalidad también en torno al $25 \%$, algo que no tiene correspondencia con el peso de la población de 65 y más años, dado que los residentes tan solo suponen el 4,4\% del total (sin perder de vista el hecho de que en las residencias no solo hay personas mayores).

De este modo, los municipios en los que se ubican residencias de ancianos presentan tasas de incidencia en población de 65 y más años superiores a los que carecen de estos centros, o que fueron capaces de blindar la entrada del virus en las mismas; algo que queda claramente reflejado en las altas incidencias de concejos como Quirós, Riosa, Soto del Barco, Piloña, Lena, Laviana, San Martín del Rey Aurelio, Siero, Gijón u Oviedo, por citar algunos de los más recientes.

\section{Discusión y conclusiones}

El análisis crítico de las fuentes disponibles para el estudio de la evolución de la COVID-19 y de su distribución espacial ha puesto de manifiesto que, aunque casi todas utilizan las mismas variables, existen notables divergencias entre ellas, lo que dificulta sustancialmente la labor de comparación a distintas escalas territoriales.

Con todo, y para no perder la perspectiva comparativa de lo ocurrido a escala nacional y a escala regional, los datos ofrecidos por el Centro Nacional de Epidemiología (CNE), dependiente del Instituto de Salud Carlos III, han servido para enmarcar el análisis de la evolución temporal de la pandemia en Asturias, comparándola con la de España.

La evolución de la pandemia en Asturias no muestra en términos globales un comportamiento claramente diferenciado con España, más allá de ligeros matices, unas veces favorables como es el caso de los resultados de la toma temprana de medidas de control o la limitación de la movilidad, tanto intrarregional como con el exterior de Asturias, otras veces negativos, como los derivados de un rápido proceso de relajación de las medidas o del efecto llamada producido por la buena situación que presentaba la región.

El análisis del comportamiento de la pandemia desde el punto de vista espacio temporal pone de manifiesto la existencia de unos marcados contrastes intrarregionales, consecuencia de los desequilibrios entre el área central, donde se concentra el grueso de la población y se dan unos elevados niveles de movilidad, y el espacio rural periférico, caracterizado por una estructura 
dispersa del poblamiento que, a la postre, se ha convertido en un elemento capaz de frenar la expansión del virus, a pesar de tratarse de las zonas con las tasas más altas de envejecimiento.

Para el caso de Asturias se concluye que la explicación de la desigualdad observada en las sucesivas fases podría ser resultado de la combinación de varias circunstancias. De un lado hay que tener presente que en los primeros momentos la capacidad de detección de personas infectadas era muy inferior a la de los meses posteriores. De otro lado, al producirse un cierre total en el primer Estado de Alarma (14 de marzo de 2020), en un momento en el en Asturias presentaba una tasa de incidencia sustancialmente menor que otras zonas de España, fue posible cortar la transmisión de forma drástica, hasta el punto de que en los meses posteriores la región llegaría incluso a estar libre de virus. De otro finalmente, para entender el repunte que se desencadenó tras el verano, hay que tener presente que los buenos datos que presentaba Asturias, unidos al cierre de los destinos turísticos exteriores, hicieron que la región se convirtiera en un reclamo para el turismo nacional. La baja incidencia durante varios meses generó una falsa sensación de seguridad, tanto entre la población local como entre la visitante, que se vio acompañada de un relajamiento de las medidas restrictivas establecidas por las distintas administraciones.

Por lo que respecta al número de fallecidos, el aspecto más reseñable es, sin duda, el gran peso de la población mayor de 65 años entre los decesos; de hecho, en lo que a la comunidad asturiana se refiere, de las 1733 muertes registradas en todo el periodo analizado, 1633, el $94,3 \%$, se produjeron en personas de 65 y más años, una proporción que se mantuvo en todas las fases de la pandemia.

La evolución temporal de los fallecimientos en Asturias y en España presenta unos rasgos generales similares, con 3 olas en fechas parecidas, aunque se pueden apreciar diferencias significativas en cuanto a la intensidad

La primera ola se desarrolló entre mediados de marzo y finales de abril de 2020, con un crecimiento muy rápido en España. La transición entre la primera y la segunda ola se prolongó a lo largo de varias semanas desde mayo a hasta finales de julio de 2020, si bien en Asturias los valores registrados permiten considerar que se dilató hasta mediados de octubre de 2020 .

En la segunda ola las diferencias entes Asturias y España son muy significativas. En el conjunto del país se desarrolló desde mediados de octubre hasta mediados de diciembre de 2020 y tuvo un desarrollo más contenido que la primera, sin llegar a alcanzar el umbral de 1 (el máximo es $0,8)$. Por el contrario, la segunda ola en Asturias fue más prolongada, de mediados de octubre 
a la primera quincena de enero de 2021, presentando, además, los peores datos de todo el periodo.

Aunque en ambos territorios el tránsito de la segunda a la tercera ola presenta un perfil parecido, con un descenso del número de fallecidos, todos los días se registró en ambos casos alguna muerte. La tercera ola se desarrolló desde enero hasta finales de febrero de 2021 siendo su máximo de 1,1 fallecidos por cada 100000 habitantes en España y de 1,7 en Asturias, con 3 días por encima de 1 a nivel nacional y 10 días en Asturias.

Las variables seleccionadas, casos diagnosticados y los datos de fallecidos, puestas en el contexto territorial, nos han permitido abordar el análisis de cuáles han sido las peculiaridades de la pandemia en cada municipio, y estudiar con especial atención los que han presentado mayores incidencias.

Se ha realizado un estudio día a día de la influencia de la pandemia en los 78 municipios asturianos, desde el 29 de febrero de 2020 hasta el 22 de marzo de 2021, es decir 360 días, pudiendo percibirse en el análisis espacial deferencias claras entre los municipios del área central y centro-sur de la región, donde se dieron los valores más altos, mientras que las zonas situadas en el interior oriental y occidental y en las "alas" del litoral registraron una menor incidencia en términos generales. En definitiva, son los municipios en los que se localizan las grandes ciudades, en las que a priori están presentes todos los factores de riesgo, los que presentan unos índices medios altos, solo matizables en términos relativos debido a su gran población.

Las diferencias entre municipios en lo que a los valores de la mortalidad se refiere tienen que ver directamente con el porcentaje de población mayor de 65 años, ya que el 94\% de los fallecidos pertenecían a este umbral, habiéndose comprobado la correlación existente entre municipios con una población envejecida, una elevada incidencia y un elevado número de fallecidos. A todo lo cual habría que añadir que se ha constatado que en los municipios en los que se localizan las residencias de ancianos, espacios en las que convive población vulnerable en espacios reducidos, que cuentan con abundantes las zonas comunes y que, por tanto, han sido importantes focos de contagio, los valores de mortalidad y de letalidad se incrementan de forma notoria.

Se considera, como línea futura de trabajo, que una desagregación territorial mayor podría ayudar a analizar los patrones de transmisión del virus; sin embargo, consideramos que no se producen condiciones especiales en dicha transmisión respecto de otros lugares, en los que nos 
consta se está trabajando por parte de equipos multidisciplinares de una manera muy eficaz para determinar y modelizar cuáles son los vectores de transmisión.

Es cierto también que un análisis más detallado podría aportar información interesante para el estudio del impacto del virus en distintos ámbitos socioeconómicos; no obstante, nuestro planteamiento ha sido el de comenzar por un análisis de datos agregados a nivel municipal, con la intención de continuar más adelante, huyendo de la inmediatez en la que nos encontramos inmersos, con el estudio a escalas de mayor detalle (parroquial y de entidades de población). Por tanto, optamos por comenzar con el desarrollo de un método de análisis deductivo, con el que hemos intentado realizar un examen de los datos municipales que nos permita llegar a algunas primeras conclusiones generales, así como a detectar singularidades territoriales, para posteriormente, con el sosiego que requiere el análisis de fenómenos tan complejos como el que estamos viviendo, abordar un estudio más detallado a partir de la consideración de las unidades territoriales menores.

Declaración responsable: Las/os autoras/es declaran que no existe ningún conflicto de interés con relación a la publicación de este artículo. Las tareas se han distribuido de la siguiente manera: el artículo ha sido coordinado por Felipe Fernández García, que se ha ocupado de la redacción de la introducción. Daniel Herrera Arenas y Cristina Fernández Bustamante han sido los encargados de la obtención de los datos, de su procesamiento y de la elaboración de la cartografía. Los tres autores han participado en el análisis de los resultados y en la primera redacción del trabajo. La versión final ha sido obra de Felipe Fernández García. 


\section{Bibliografía}

Aalbers, M. B., Beerepoot, N., \& Gerritsen, M. (2020). Editorial: The Geography of the COVID19 Pandemic. Tijdschrift Voor Economische En Sociale Geografie, 111(3), 201204. https://doi.org/10.1111/tesg. 12456

Ascani, A., Faggian, A., \& Montresor, S. (2021). The geography of COVID-19 and the structure of local economies: The case of Italy. Journal of Regional Science, 61(2), 407441. https://doi.org/10.1111/jors. 12510

Bissell, D. (2021). A changing sense of place: Geography and COVID-19. Geographical Research, 59(2), 150-159. https://doi.org/10.1111/1745-5871.12465

Boterman, W.R. (2020). Urban-Rural Polarisation in Times of the Corona Outbreak? The Early Demographic and Geographic Patterns of the SARS-CoV-2 Epidemic in the Netherlands. Tijdschrift Voor Economische En Sociale Geografie, 117(3), 513529. https://doi.org/10.1111/tesg. 12437

Buj, A.B. (2020). La COVID-19 y las viejas epidemias. No es la Tercera Guerra Mundial, es el capitalismo. Ar@cne: revista electrónica de recursos en internet sobre geografía y ciencias sociales. https://www.raco.cat/index.php/Aracne/article/view/367759

Buzai, G.D. (2020). Geografía y sistemas de información geográfica en contexto del COVID-19. Geografía y Sistemas de Geografía y Sistemas de Información Información Geográfica (GeoSIG). http://ri.unlu.edu.ar/xmlui/handle/rediunlu/799

Casti, E. (2020). Geografia a "vele spiegate". Analisi territoriale e mapping riflessivo sul COVID-19 in Italia. Documenti geografici, 01 -

83. https://doi.org/10.19246/DOCUGEO2281-7549/202001_03

Chen, A. (2020). A socio-spatial research agenda on the COVID-19 pandemic. Acta Sociologica, 63, 453-456. https://doi.org/10.1177/0001699320961811

Connolly, C., Ali, S. H., \& Keil, R. (2020). On the relationships between COVID-19 and extended urbanization. Dialogues in Human Geography, 10(2), 213216. https://doi.org/10.1177/2043820620934209

CSIC (2021). Mapa de recursos sociales y sanitarios.

Residencias. http://envejecimiento.csic.es/recursos/residencias/index.htm 
De Cos, O., Castillo, V., \& Cantarero, D. (2021). Differencing the Risk of Reiterative Spatial Incidence of COVID-19 Using Space-Time 3D Bins of Geocoded Daily Cases. ISPRS International Journal of Geo-Information, 10(4), 261. https://doi.org/10.3390/ijgi10040261

Dummont, G.-F. (2020). Covid-19: ¿El principio de una revolución geográfica? Population et avenir. Association Population et Avenir, 3. https://halshs.archives-ouvertes.fr/halshs$\underline{03013661 / \text { document }}$

Fernández, L. V. S., González, P. A., Vela, R. N., \& Martín, E. H. (2019). La pandemia de gripe de 1918-1919 en territorio asturiano: De padecimiento histórico a enfermedad emergente cien años después / The Influenza pandemics of 1918-1919 in Asturian territory: Analysis of a 100year process going from historical suffering to emerging disease. Ería, 7997. https://doi.org/10.17811/er.1.2019.79-97

Franch-Pardo, I., Napoletano, B. M., Rosete-Verges, F., \& Billa, L. (2020). Spatial analysis and GIS in the study of COVID-19. A review. Science of The Total Environment, 739, 140033. https://doi.org/10.1016/j.scitotenv.2020.140033

Gialis, S., \& Kapitsinis, N. (2020). The impact of Covid-19 pandemic on youth employment: A southern EU perspective (pp. 11-19).

González Pérez, J.M. (2020). La ciudad desigual en Palma (Mallorca): Geografía del confinamiento durante la pandemia de la COVID-19 | Boletín de la Asociación de Geógrafos Españoles. Boletín de la Asociación de Geógrafos Españoles,

\section{7. https://doi.org/10.21138/bage.2998}

Hauser, F. (1887). Estudios epidemiológicos relativos á la etiología y profilaxis del cólera basados en numerosas estadísticas, hechos y observaciones recogidos durante la epidemia colérica de 1884-85 en España y acompañados de 18 mapas y 25 cuadros estadísticos, 3 vols. Y Atlas in fol. (Vol. 1-3 y Atlas in fol). Imprenta y Fundación de Manuel Tello/Est. Tipográfico de El Correo; http://bdh-rd.bne.es/viewer.vm?id=0000239709\&page=1.

Hempel, S. (2020). Atlas de epidemias Enfermedades mortales y contagiosas desde la peste hasta el virus del Zika. Librero.

Herrera, D. (Daniel Herrera). (2021a, November 30). Incidencia Mensual [Video]. Youtube. https://youtu.be/P5RHliOUmpU

Herrera, D. (Daniel Herrera). (2021b, November 30). Incidencia Acumulada Mensual [Video]. Youtube. https://youtu.be/pfbNUzHbV48 
Herrera, D. (Daniel Herrera). (2021c, November 30). Incidencia Mensual en mayores de 65 años [Video]. https://youtu.be/jWba-oUw9Oc

Herrera, D. (Daniel Herrera). (2021d, November 30). Incidencia Acumulada Mensual en mayores de 65 años [Video]. Youtube. https://youtu.be/jPfiXpQfgqQ

Herrera, D. (Daniel Herrera). (2021e, Noviembre, 30). Incidencia Mensual de fallecidos [Video]. Youtube. https://youtu.be/WGwBOf-UU10

Herrera, D. (Daniel Herrera). (2021f, November 30). Incidencia Acumulada Mensual de fallecidos [Video]. Youtube. https://youtu.be/6Q4Fp1siXBE

Herrera, D. (Daniel Herrera). (2021g, November 30). Incidencia Mensual de fallecidos en mayores de 65 años [Video]. Youtube. https://youtu.be/4RPHvOB5RVc

Herrera, D. (Daniel Herrera). (2021h, November 30). Incidencia Acumulada Mensual de fallecidos en mayores de 65 años [Video]. Youtube. https://youtu.be/8ySra1RiTgQ

Herrera, D. (Daniel Herrera). (2021i, November 30). Letalidad [Video]. Youtube. https://youtu.be/Xt9knY1ToJY

Herrera, D. (Daniel Herrera). (2021j, Noviembre, 30). Letalidad en mayores de 65 años [Video]. Youtube. https://youtu.be/Xt9knY1ToJY

Holmager, T., Lynge, E., Kann, C., \& St-Martin, G. (2020). Geography of COVID-19 in Denmark. Scandinavian Journal of Public Health, 49, 140349482097560. https://doi.org/10.1177/1403494820975607

Kapitsinis, N. (2020). The underlying factors of the Covid-19 spatially uneven spread. Initial evidence from regions in 9 EU countries. Regional Science Policy \& Practice, 12. https://doi.org/10.1111/rsp3.12340

Kapitsinis, N., \& Sykas, G. (2020). A brief overview on the uneven impact of the Covid-19 pandemic upon employment and the young NEETs: Evidence from Greek regions and sectors Brief Report by Nikos Kapitsinis, George Sykas and the «COVID-19_Regional_Labour» team *. https://doi.org/10.13140/RG.2.2.10128.84480

Klapka, P., Ellegård, K., \& Frantál, B. (2020). What about Time-Geography in the post-Covid-19 era? Moravian Geographical Reports, 28, 238-247. https://doi.org/10.2478/mgr-2020-0017 
Krzysztofik, R., Kantor-Pietraga, I., \& Spórna, T. (2020). Spatial and functional dimensions of the COVID-19 epidemic in Poland. Eurasian Geography and Economics, 61(4-5), 573586. https://doi.org/10.1080/15387216.2020.1783337

Kuebart, A., \& Stabler, M. (2020). Infectious Diseases as Socio-Spatial Processes: The COVID-19 Outbreak In Germany. Tijdschrift Voor Economische En Sociale Geografie, 117(3), 482496. https://doi.org/10.1111/tesg. 12429

Marques da Costa, E., \& Marques da Costa, N. (2020). Covid 19 - Expressão geográfica do número de casos confirmados em Portugal: 29 de Abril 2020. Boletim Covid 19: expressão geográfica do número de casos confirmados em Portugal,

3. https://repositorio.ul.pt/handle/10451/43253

Mooney, P., \& Juhász, L. (2020). Mapping COVID-19: How web-based maps contribute to the infodemic. Dialogues in Human Geography, 10(2), 265270. https://doi.org/10.1177/2043820620934926

Moreno, C. (2020). La cartografía digital generada por la COVID-19: Análisis y tipologías = The digital cartography generated by COVID-19: Analysis and typologies. Espacio Tiempo y Forma. Serie VI, Geografía, 103. https://doi.org/10.5944/etfvi.13.2020.27806

Observatorio de Salud en Asturias (2021). Coronavirus en Asturias. Informe 2020-21. Gobierno del Principado de Asturias. https://obsaludasturias.com/obsa/wpcontent/uploads/MORBILIDAD-CON-CORONAVIRUS-EN-ASTURIAS_INFORME-ANO-

CALENDARIO-2021.pdf

Ocaña-Riola, R., \& Sanchez-Cantalejo, C. (2020). Epidemiología y análisis espacial. DEMAP, 146-153.

Perez-Bermejo, M., \& Murillo-Llorente, M. (2020). The fast territorial expansion of the Covid-19 in Spain. Journal of Epidemiology, 30. https://doi.org/10.2188/jea.JE20200123

Perles, M.J., Sortino, J. F., \& Mérida, M. F. (2021). The Neighborhood Contagion Focus as a Spatial Unit for Diagnosis and Epidemiological Action against COVID-19 Contagion in Urban Spaces: A Methodological Proposal for Its Detection and Delimitation. International Journal of Environmental Research Public Health, 18(6), 3145. https://doi.org/10.3390/ijerph18063145 
Pinzón, J. E. D. (2020). Análisis de los resultados del contagio del COVID-19 respecto a su distribución geográfica en Colombia. Revista Repertorio de Medicina y Cirugía, 6064. https://doi.org/10.31260/RepertMedCir.01217372.1082

Ramirez, L. (2020). Evolución, distribución y difusión del COVID-19 en Argentina: Primer mes (03/03/2020 - 02/04/2020). http://ri.unlu.edu.ar/xmlui/handle/rediunlu/684

Remus, C., \& Light, D. (2020). COVID-19 in Romania: Transnational labour, geopolitics, and the Roma 'outsiders'. Eurasian Geography and Economics, 61, 559572. https://doi.org/10.1080/15387216.2020.1780929

Reuschke, D., \& Felstead, A. (2020). Changing workplace geographies in the COVID-19 crisis. Dialogues in Human Geography, 208212. https://doi.org/10.1177/2043820620934249

Robinson, C., Rowe, F., \& Patias, N. (2020). The Geography of the COVID-19 Pandemic in England. https://doi.org/10.5281/zenodo.4333313

Rose-Redwood, R., Kitchin, R., Apostolopoulou, E., Rickards, L., Blackman, T., Crampton, J., Rossi, U., \& Buckley, M. (2020). Geographies of the COVID-19 pandemic. Dialogues in Human Geography, 10(2), 97-106. https://doi.org/10.1177/2043820620936050

Sardon, J.-P. (2020). De la longue histoire des épidémies au Covid-19. Les Analyses de Population Avenir, 26(8), 1-18.

Scala, A., Flori, A., Spelta, A., Brugnoli, E., Cinelli, M., Quattrociocchi, W., \& Pammolli, F. (2020). Between Geography and Demography: Key Interdependencies and Exit Mechanisms for COVID-19 (SSRN Scholarly Paper ID 3572141). Social Science Research Network. https://doi.org/10.2139/ssrn.3572141

Sun, F., Matthews, S. A., Yang, T.-C., \& Hu, M.-H. (2020). A spatial analysis of the COVID-19 period prevalence in U.S. counties through June 28, 2020: Where geography matters? Annals of Epidemiology, 52, 54-59.e1. https://doi.org/10.1016/j.annepidem.2020.07.014

Wheaton, W.C., \& Kinsella Thompson, A. (2020). The Geography of COVID-19 Growth in the US: Counties and Metropolitan Areas (SSRN Scholarly Paper ID 3570540). Social Science Research Network. https://doi.org/10.2139/ssrn.3570540 
Yılmaz, S. (2020). Covid-19 and territory: searching for a secure place. In III International Conference on COVID-19 Studies (pp. 279-285). New York, January 1617. https://www.researchgate.net/publication/347986387_COVID19_AND_TERRITORY_SEARCHING_FOR_A_SECURE_PLACE 